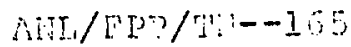

0583005943

ANL/FPP/TM-165
Distribution Category:

Magnetic Fusion Energy

(UC-20)

ARGONNE NATIONAL LABORATORY

9700 South Cass Avenue

Argonne, I11inois 60439

\title{
TRITIUM BREEDING IN FUSION REACTORS
}

by

Kohaned A. Abdou

Fusion Power Program

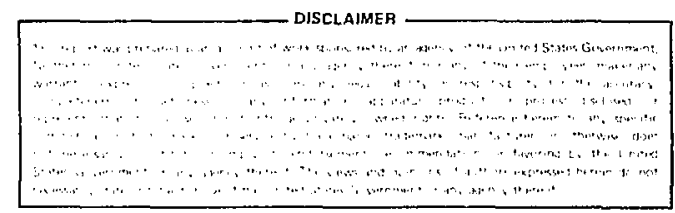

October 1982

*Invited paper presented at the International Conference of Nuclear Data for Science and Technology, September 6-10, 1982, Antwerp, Belgium. 
ABSTRACT $\ldots \ldots \ldots \ldots \ldots \ldots \ldots \ldots \ldots \ldots \ldots \ldots \ldots \ldots \ldots \ldots \ldots \ldots \ldots \ldots \ldots \ldots \ldots \ldots \ldots$

1. Introduction. .........................................

2. Breeding Blanket Design and Materials........................ 2

3. Tritium Breeding Requirements,.......................... 8

4. Breeding Potential of Candidate Materials.........................

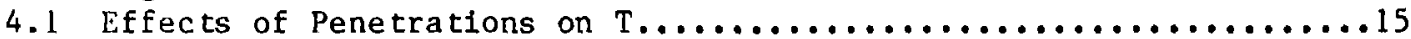

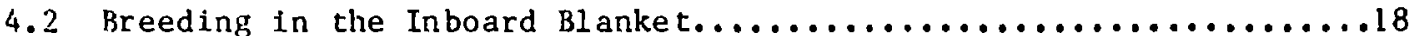

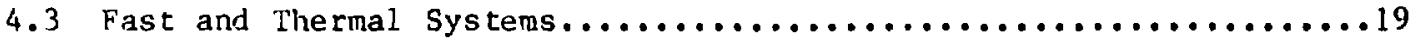

4.4 Neutron Multipliers....................................24

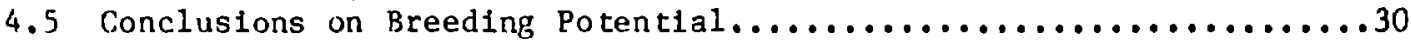

5. Sensitivity to Data Incertainties.............................

6. Recommended Effort................................... 40

7. Nuilear Data Needs....................................44

References.............................................49 


\section{LIST OP FIGURES}

FIGURE NO.

TITLE

PAGE

1

3

4

5

$6 a$

$6 \mathrm{~b}$

$7 a$

$7 \mathrm{~b}$

8

$17 \mathrm{Li}-83 \mathrm{~Pb}$ liquid alloy breeder first wall/blanket

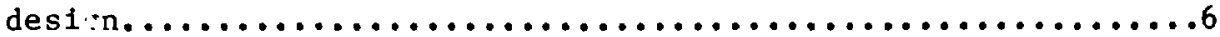

$\mathrm{Li}_{2} \mathrm{O}$ solid breeder reference design first wall/blanket........9

DEMO reference design............................10

Effect of fractional burnup and doubling time upon

required breeding ratio...........................2

Vertical cross section of the toroidal geometry used

for Monte Carlo calculations.........................17

Neutron spectrum in three blanket systems: $\mathrm{LI}_{2} \mathrm{O}, \mathrm{L1}$ and $17 \mathrm{Li}-83 \mathrm{~Pb}$. The systems are described in Table $\mathrm{V}$.

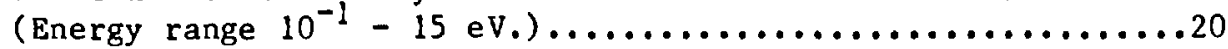

Neutron spectrum in three blanket systems: $\mathrm{Li}_{2} \mathrm{O}, \mathrm{Li}$ and $17 \mathrm{Li}-83 \mathrm{~Pb}$. The systems are described in Table $\mathrm{V}$. (Energy range $10^{-1}-10^{5}$ ev.).

Neutron spectrum in $\mathrm{LiAlO}_{2}$ blanket with beryllium multiplier. The system consists of $1 \mathrm{~cm}$ first wall (Zone 1), $4 \mathrm{~cm} \mathrm{LiAlO}$ (Zone 2), $8 \mathrm{~cm}$ Be (Zone 3), $20 \mathrm{~cm} \mathrm{LiAlO}_{2}$ (Zone 4). Curves a and $b$ are for the first and last points, respectively, in Zone 2 . Curves $c$ and $d$ are for the first and midpoint of Zone 4. (Energy range $0.1-15 \mathrm{MeV}$.)....................22

Neutron spectrum in $\mathrm{LiAlO}_{2}$ blanket with beryllium multiplier. The system consists of $1 \mathrm{~cm}$ first wall (Zone 1), $4 \mathrm{~cm} \mathrm{LiAlO}$ (Zone 2), $8 \mathrm{~cm}$ Be (Zone 3), $20 \mathrm{~cm} \mathrm{LiAlO}_{2}$ (Zone 4). Curves $\mathrm{a}$ and $\mathrm{b}$ are for the first and last points, respectively, in Zone 2 . Curves $c$ and $d$ are for the first and midpoint of

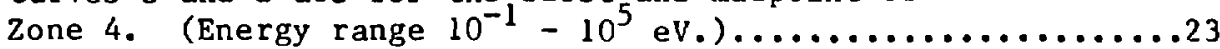

Tritium breeding ratio from the separate zone blanket option with different neutron multipliers (internally cooled) with $\mathrm{LiAlO}_{2}\left(90 \%{ }^{6} \mathrm{Li}\right)$ breeder, $\mathrm{H}_{2} \mathrm{O}$ coolant and PCA structure.....................................29

Possible arrangenents of solid breeder and solid neutron mul tiplier.................................. 


\section{LIST OF TABLES}

TABLE NO.

TITLB

PAGE

I

II

III

IV

v

VI

VII

VIII

IX

$\mathrm{x}$

$X I$

XI I

XIII

$X I V$

XV

XVI

XVII
Important Areas of Nuclear Data for Fusion...............4

Candidate First-Wall/Blanket Materials..................4

Critical Issues for the Breeder Blanket Options............7

Promising Blanket Concepts Under hetlue Consideration........16

Description of Four Blanket Designs for Tritium

Breeding Calculations............................16

Tritium Breeding Ratio Potential (Full breeding

blanket coverage with no penetrations.) .................17

Tritium Breeding Ratio with and without Inboard

Blanket and Limiter..............................20

Properties of Candidate Neutron Multiplier Materials........26

Blanket Parameters for Internally-Cooled Neutron

Multiplier Concepts..................................29

Estinated Tritium Breeding Ratio Likely to be

Achievable in Fusion Power Reactors....................31

Description of Two Blanket Concepts for Sensitivity

(Analysis performed by Alsmiller, et al ${ }^{35}$.)................ 34

Cross Section Uncertainties Due to the Cross Section

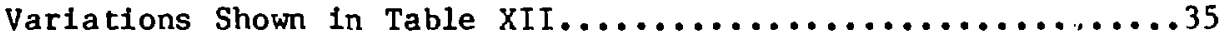

Breeding-Ratio Uncertainties Due to the Cross Section

Variations Shown in Table XII...............................

INTOR Blanket Models used by Pelloni ${ }^{39} \ldots \ldots \ldots \ldots \ldots \ldots \ldots \ldots . \ldots 38$

Sensitivities 39 of Trictum Production Rate to Partial

Cross Section Uncertainties for the Two INTOR Designs

of Table XIV (Percent per $1 \%$ Cross Section Increase.).........39

Needed Neutronics Effort on Tritium Breeding.............42

Probability of Use and Priority of Data Needs for

Elements of Importance to Tritium Breeding................46 


\title{
TRITIUM BREEDING IN FUSION REACTORS
}

by

\author{
Mohamed A. Aüdou
}

\begin{abstract}
Key technological problems that influence tritium breeding in fusion blankets are reviewed. The breeding potential of candidate materials is evaluated and compared to the tritium breeding requirements. The sensitivity of tritium breeding to design and nuclear data parameters is reviewed. A framework for an integrated approach to improve tritium breeding prediction is discussed with emphasis on nuclear data requirements.
\end{abstract}

\section{Introduction}

The first generation of commercial fusion reactors will operate on the DT cycle. In comparison with other fusion cycles, the DT cycle has technological requirements that are more attainable in the near term and power reactor economics that are more favorable. A self-sustaining DT fusion reactor must breed tritium. In all fusion reactor concepts, this is accomplished in a lithium-containing blanket that circumscribes the plasma.

The feasibility of producing tritium with an adequate breeding ratio TBR was a serious issue in the 1950's and early $1960^{\prime} \mathrm{s}$. The release of reasonable data for the ${ }^{7}$ Li $\left(n, n^{-} \alpha\right)$ t reaction led to estimates of $T B R>1$ in the 1960's. The early generation ${ }^{1,2}$ of conceptual designs predicted TBR of $\sim 1.3$ to 1.5 for natural-lithium blankets with full coverage. Early sensitivity studies $^{3}$ showed that the TBR in the natural lithium system was not overly sensitive to variations in cross sections. Consequently, concerns about attaining adequate TBR were alleviated and tritium breeding studies were not given high priority for most of the $1970^{\prime} \mathrm{s}$.

The safety problems of liquid lithium received a great deal of attention in the past several years. The STARFIRE ${ }^{4}$ and DEMO ${ }^{5}$ studies investigated breeder blanket concepts based on solid $1 i$ thium compounds such as $\mathrm{Li}_{2}{ }^{0}$, 
$\mathrm{LiAlO}_{2}$, and $\mathrm{Li}_{2} \mathrm{SiO}_{3}$. Solid breeders appear now to be the leading candidates worldwide ${ }^{6}$ for fusion blankets. However, the feasibility of solid breeders has not yet been established. Achieving adequate tritium breeding and acceptable tritium recovery from the blanket are the two most critical issues for solid breeders. Thus, the past three years have witnessed a serious interest in the tritium breeding issues.

This review paper is concerned with tritium breeding in fusion blankets. While the discussion of nuclear data is the primary motivation for this paper, the author avoids the conventional approach of providing a simple list of recommendations for a few cross sections to be measured. Rather, the paper is written to help nuclear-data specialists develop an appreciation of the many technological variables of the tritium breeding issue in fusion blankets. A selected number of the most promising design concepts for the breeding blanket are described. The breeding potential of candidate breeding materials and blanket designs is evaluated and compared to the tritium breeding requirements. The sensitivity of tritium breeding to design and nuclear data parameters is reviewed. Finally, a framework for an integrated approach to improve tritium breeding prediction is discussed.

There are many areas of fusion applications where nuclear data is important. Some of these are indicated in Table I. This paper is focused only or tritium breeding. The nuclear data requirements for other areas have been reviewed by a number of authors (see for example references 9, 42, 43, and 46 !.

The plans for the major fusion programs $i$ in the world call for a tritiumproducing blanket in a fusion engiveering device whose construction will start in the early 1990's. Hrwever, the requirements for improvements in the nuclear data base for tritium breeding must be satisfied much sooner--over the next several years. Accurate data is required now because it constitutes an important part of the input to evaluating the feasibility of the many design concepts and candidate breeding materials that are now under consideration.

\section{Breeding Blanket Design and Materials}

The primary functions of the blanket in a fusion reactor system is to convert the energy of the fusion neutrons into sensible heat and to breed tritium. The present focus of the blanket development is on defining a 
compatible combination of materials that can be integrated into a functional design. This design must serve the following requirements:

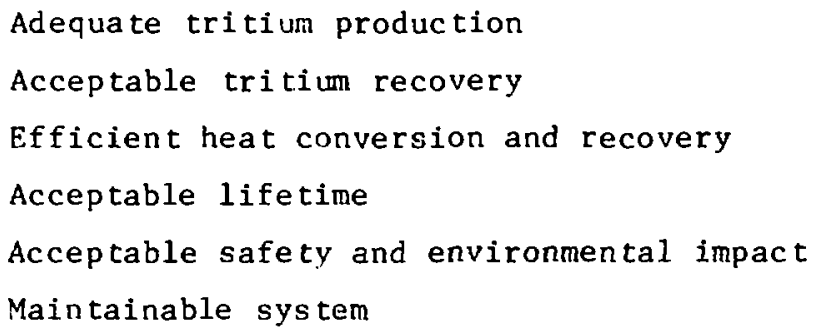

The blanket contains a number of materials, including a lithium-bearing material for tritium breeding and a structural material for containing the coolant. Some breeding materials require a neutron multiplier in order to achieve adequate breeding ratio. Lithium is not a very efficient moderator, and in some blanket concepts, another material is used for neutron slowing down. A reflector is normally incorpoated at the outer end of the blanket. Table II lists the candidate blanket materials that are now under consideration in fusion development.

A large number of blanket designs have been proposed and evaluated in design studies. The promising concepts can generally be classified into the following types:

1. Liquid Metal

a. liquid metai as breeder and coolant

b. liquid metal as breeder and a separate coolant

2. Solid Breeder (with separate coolant).

The candidate liquid metals are 1 ithium, $\mathrm{Li}_{17} \mathrm{~Pb}_{83}$ and $\mathrm{LiBi}_{5} \mathrm{~Pb}_{4}$. They can be used as both the breeder and coolant or as the breeder alone with a separate coolant. $\mathrm{LiBi}_{5} \mathrm{~Pb}_{4}$ and $\mathrm{Li}_{17} \mathrm{~Pb}_{83}$ are very similar in many respects, particularly the neutronics characteristics. $\mathrm{LiBi}_{5} \mathrm{~Pb}_{4}$ has the advantage of a lower melting point but the large polonium production in bismuth makes it less 
Table I. Important Areas of Nulcear Data for Fusion

\begin{tabular}{|c|c|}
\hline Applications & Comments \\
\hline Fuel Cycle & $\begin{array}{l}\text { Charged particle reactions for DT, DD and advanced } \\
\text { fuels. }\end{array}$ \\
\hline Tritivi Dreeding & $\begin{array}{l}6_{L I}(n, \alpha) t,{ }^{7} L i\left(n, n^{-} \alpha\right) t, \text { neutron emission and } \\
\text { parasitic aboorption for blanke = naterials. }\end{array}$ \\
\hline Nuclear Heating & $\begin{array}{l}\text { Neutron and gama transport neutron reaction } \\
\text { kinetics, reaction Q-values. }\end{array}$ \\
\hline Radiation Damage & DFA, gas production, transqutation. \\
\hline Induced Activity & Trangmutation reactions, decay schemes. \\
\hline Radiation Shlelding & $\begin{array}{l}\text { Shlelding of components and personnel; neutron and } \\
\text { gamma transport, induced activity, hesting. }\end{array}$ \\
\hline
\end{tabular}

Table II. Candidate First-Wal1/Blanket Materials

\begin{tabular}{|c|c|c|c|}
\hline Breeding Matertals & Coolants & Structure & Neutron Multiplier \\
\hline 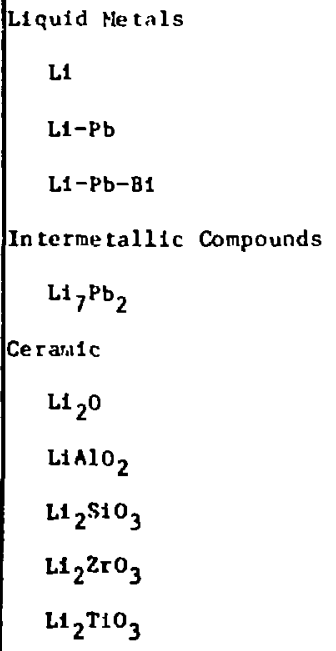 & 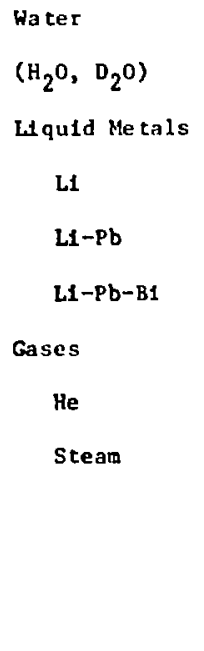 & $\begin{array}{l}\text { Austenltic Stalnless Steel } \\
\text { Ferritic Steels } \\
\text { Nickel-base alloys } \\
\text { Refractory Alloys (e.g., v) }\end{array}$ & $\begin{array}{l}\mathrm{Be} \\
\mathrm{BeO} \\
\mathrm{Pb} \\
\mathrm{PbO} \\
\mathrm{BI} \\
\mathrm{Zr} \\
\mathrm{Zr}_{5} \mathrm{~Pb}_{3} \\
\mathrm{PbBt}\end{array}$ \\
\hline
\end{tabular}


favorable. Water cannot be used as a coolant with liquid lithium because of their strong chemical reactivity and unacceptable safety consequences. The reactivity $\mathrm{O}_{i}$ water with $\mathrm{Li}_{17} \mathrm{~Pb}_{83}$ is much lower than with liquid 11 thium, and water cooling in $\mathrm{Li}_{17} \mathrm{~Pb}_{83}$ is believed to be acceptable. Sodium and helium are other candidate coolants for liquid metal breecers.

Figure 1 is a cross section of a representative liquid metal blanket with a separate coolant. The dimensions in the figure are approximately to-scale and are based on the $\mathrm{Li}_{17} \mathrm{~Pb}_{83}$ blanket design developed in the STARFIRE/DEMO study.

There are a number of critical issues for the liquid metal blankets, as shown in Table III. The very strong reactivity of lithium with air and water is an important safety issue. For both lithium and lithium-lead, the compatibility with the structural material and MHD effects are key issues. Resolving the compatibility issue may require the development of a structural alloy other than austenitic stainless steel, which is believed to be a costly and time-consuming development.

The above issues have led recently to serious consideration of solid breeders. The most promising solid breeders are $\mathrm{Li}_{2} \mathrm{O}$ and the ternary ceramics: $\mathrm{LiAlO}_{2}, \mathrm{Li}_{2} \mathrm{SiO}_{3}$ and $\mathrm{Li}_{2} \mathrm{ZrO}_{3}$. The most critical issues for solid breeders are achieving adequate tritium breeding and acceptable tritium recovery (see Table III). The tritium breeding issue will be discussed in the following sections. It remains to be demonstrated that the steady-state tritium inventory in solid breeders can be kept acceptably low ( $<10 \mathrm{~kg}$ ) under irradiation. Both helium and water have been proposed for use as coolants with solid breeders. It has been shown ${ }^{11}$ that pressurized water is superior to helium under present materials and reactor design constraints. The loss of radiation-attenuating space associated with the use of helium in the inboard blanket results in a large economic penalty. Furthermore, the higher operating temperature required for helium requires a structural material other than austenitic stainless steel. The void space and the additional increase in the structural material volume required for helium also reduce the achievable tritium breeding ratio.

Li thium oxide is presently considered to be the most promising solid breeder, primarily because its breedilg potential is higher than that for the ternary ceramics. One of the key problems with $\mathrm{Li}_{2} \mathrm{O}$ is 1 ts reactivity with 
Figure 1.

\section{Li-83Pb LIQUID ALLOY BREEDER FIRST} WALL/BLANKET DESIGN

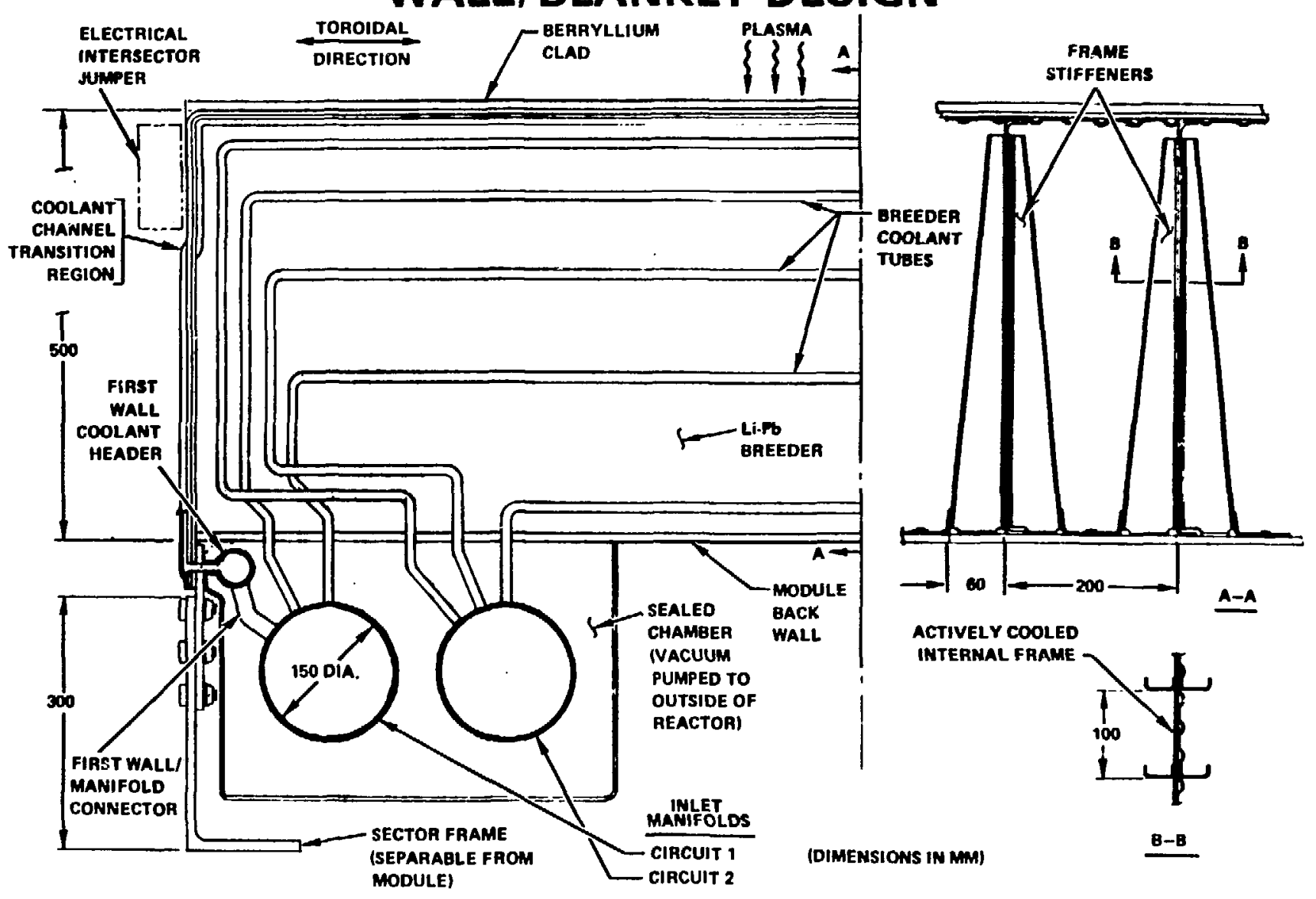


Table III. Critical Issues for the Breeder Blankat Options

\section{LIQUID METALS}

A. Lithium

- Safety

Consequences of Lithium fire

- MWD Effects

- Compatibilfty with Structural. Materials

B. $17 L A-83 P b$

- Compatilility wi th Structural Materiale

- For L1-Pb Cooling

- MDD Ef fects

- Tritium Processing and Containment

- For Water Cooling

- Safety - large scale expulsion of L1-Pb from the blanket In offnormal L1-Pb/water contact

- Tritium permeation to water as a result of tritium low solubllity/high pastial pressure

- For Sodiun Cooling

- Safety - chemical reactivity of sodium with water and air

- MHD Effects

\section{SOLID BREEDERS}

Blanket Tritium Inventory

Part sularly, effects of radiation on tritium inventory.

Design Practicabllity

A number of design problens related to maintaining the low-thermalconductivity breeder material within the required narrow temperature range and cortitroling the temperature gradtent at the breeder/structure/coolant interfaces.

- For $\mathrm{HAlO}_{2}$ : Tritlum Breeding

Achleving a net tritlum breeding ratio greater than one.

- Por $\mathrm{LI}_{2}$ 0: Reactivity with Water to Form LIOH

- Difficulties in obtaining and maintaining high purity Li, 0 .

- Consequences of corrosive effects of LiOf under off-ncismal events Involving breeder/coolant interaction. 
water to form the highly corrosive $\mathrm{LIOH}$. The ternary ceramics (e.g., $\mathrm{LiAlO}_{2}$ ) are more chemically stable bit their tritium breeding is questionable, as discussed later.

Figure 2 shows a cross section of a typical design for a solid breeder blanket. The details are based on the $\mathrm{Li}_{2} \mathrm{O}$ design for the STARFIRE/DEMO. 5 figure 3 is a vertical cross section of a tokamak and shows the 1nterrelation between the blanket and other components.

\section{Tritiu Breeding Requirenents}

The triti:m breeding ratio is defined as $T=\mathrm{N}^{+} / \mathrm{N}^{-}$, where $\mathrm{N}^{+}$is the rate of sritiun production in the system (normally the blanket) and $\dot{\mathrm{N}}^{-}$is the rate of burning tritium in the plasma. T must exceed unity by a margin (G) to cover 1) losses and radioactive decay during the period between production and use, and 2) supplying inventory for startup of other fusion reactors. Detailed expressions were derived 7,8 to correlate $T$, doubling time $\left(t_{d}\right)$, and inventory. The expression has the general form

$$
T=1+\frac{I D}{N^{-} t_{d}}
$$

where $I$ is the total tritium inventory and $D$ is a complex function that accounts for radioactive decay and other losses. The magnitude of the total tritium inventory is determined by the tritium inventories in the breeding blanket $\left(I_{B}\right)$, fueling and exhaust systems $\left(I_{F}\right)$, storage $\left(I_{S}\right)$, and startup $\left(\mathrm{I}_{0}\right)$, respectiveiy. At present, there are large uncertainties concerning the magnitude of the tritium inventory achievable in fusion reactor systems. The tritium inventory in the blanket will be $<1 \mathrm{~kg}$ for liquid lithium systems, but may be between 1 and $10 \mathrm{~kg}$ or greater in solid breeders because their tritium release characteristics cannot be quantified at present. The magnitude of $I_{F}$ depends strongly on many plasma-perrormance and exhaust-system operating parameters such as the fractional tritium burnup in the plasma. $I_{S}$ is determined by the amount of fuel required in reserve to guard against a temporary malfunction of the tritium recovery system. $I_{0}$ is the tritium inventory that needs to be accumulated in order to start up a new reactor, and it is also a function of $I_{B}, I_{F}$ and $I_{S}$ * 
Figure 2.

\section{Li2O SOLID BREEDER REFERENCE DESIGN FIRST WALL/BLANKET}

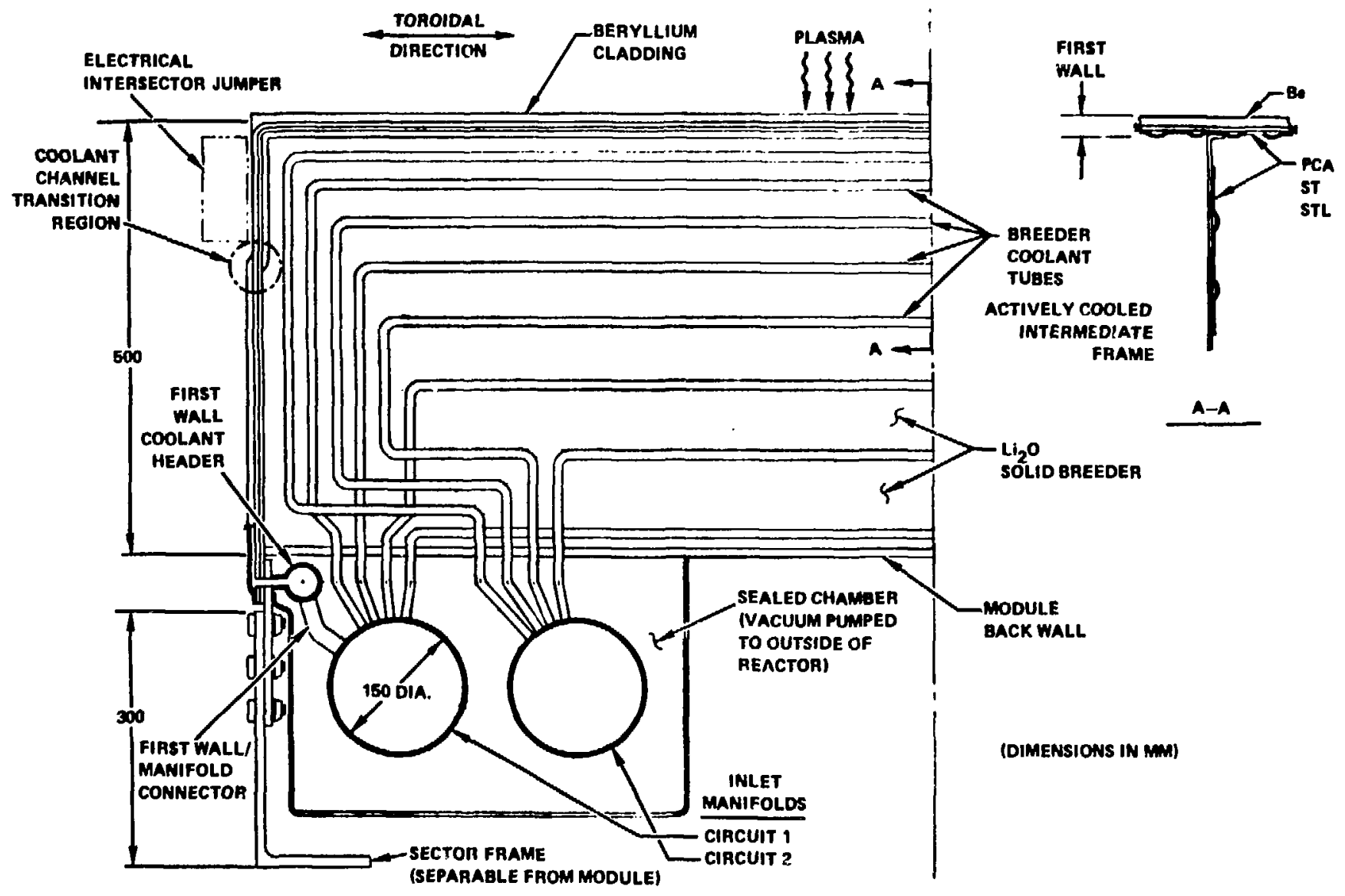


Figure 3.

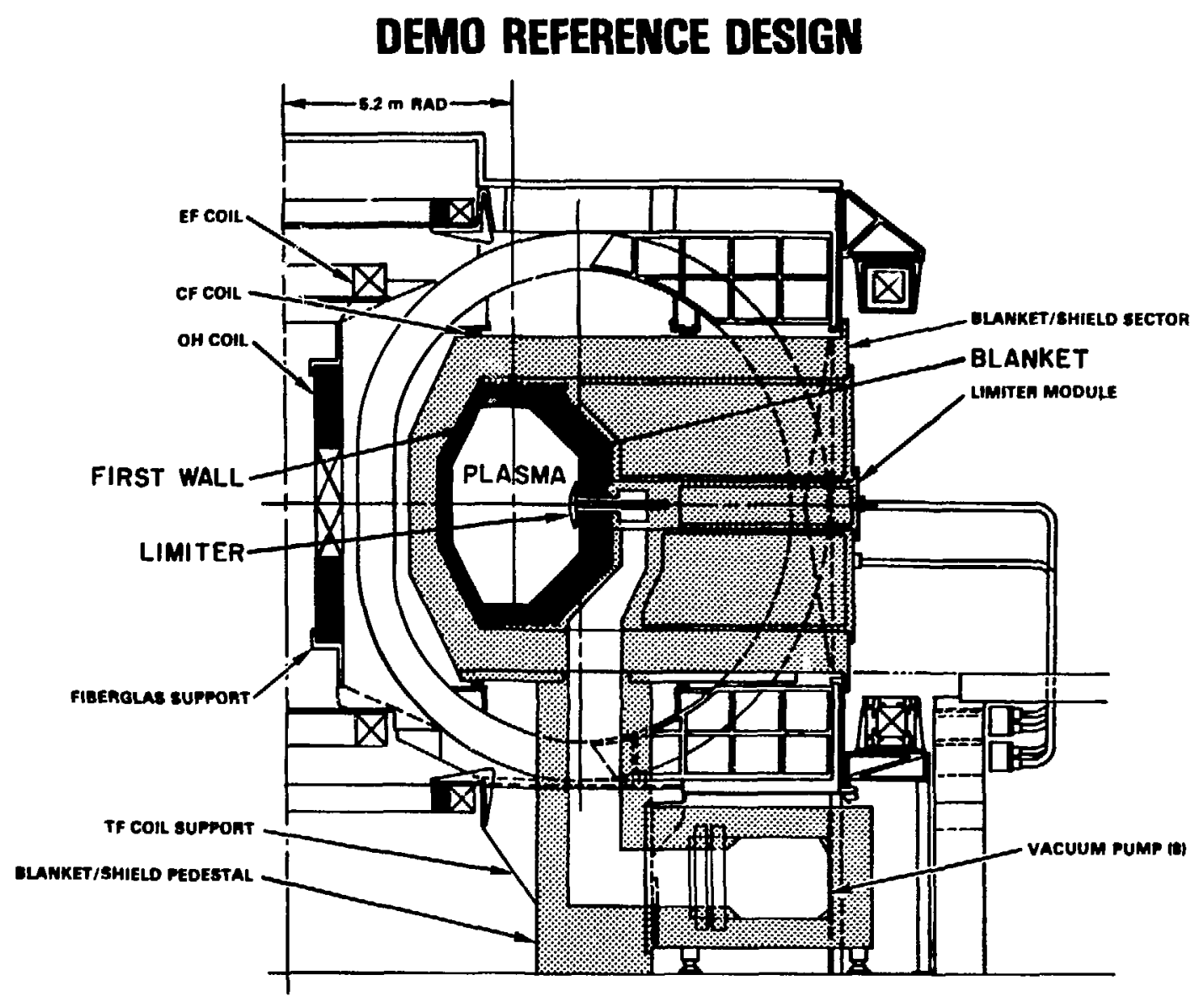


Figure 4 shows the required tritium breeding ratio as a function of the fractional tritium burnup in the plasma and the doubling time assuming the blanket tritium inventory is $10 \mathrm{~kg}$. The required tritium breeding ratio increases very rapidly as the fractional burnup decreases to $\sim 1 \%$ and as $t_{d}$ becomes very short. This is one of the reasons why achieving a fractional burnup of $>5 \%$ has been identified as one of the key goals for the impurity control and exhaust system development. The doubling-time goal is obviously related to the desired growth rate for fusion power. The historical growth of the power industry has been a doubling time of $\sim 10$ year. For the first generation of fusion power reactors, a short doubling time $(<5 \mathrm{y})$ is highly desirable.

The required tritium breeding ratio $\left(\mathrm{T}_{0}\right)$ in an actual operating raactor should thus be

$$
T_{0}=1+G
$$

where $G$ is the margin discussed above. For a fractional burnup of $\sim 5 \%$ and doubling time of $\sim 5 \mathrm{y}$ the required $\mathrm{T}_{0}$ is $\sim 1.05$. It should be clearly realized that if a fractional burnup of only $\sim 1 \%$ is achievable, then the required $\mathrm{T}_{0}$ is $\sim 1.2$-- a very difficult breeding requirement to achieve as will become evident in later sections.

$\mathrm{T}_{0}$ as defined in Eq. 2 is the actual net tritium breeding ratio that must be obtained in an operating fusion power reactor. The more difficult task is establishing the goal for the tritium breeding ratio $\left(T_{D}\right)$ that must be achieved in a conceptual design. Clearly, $\mathrm{T}_{\mathrm{D}}$ must exceed $\mathrm{T}_{0}$ by an allowance $(\Delta)$ for the uncertainties in estimating $T_{0}$, i.e.,

$$
T_{D}=1+G+\Delta
$$

The sources of uncertainties in estimating $\Delta$ are numerous, but can be broadly classified into three areas: 1) reactor design definition, 2) neutronics calculations, and 3) nuclear data. A few comments on these are in order. 


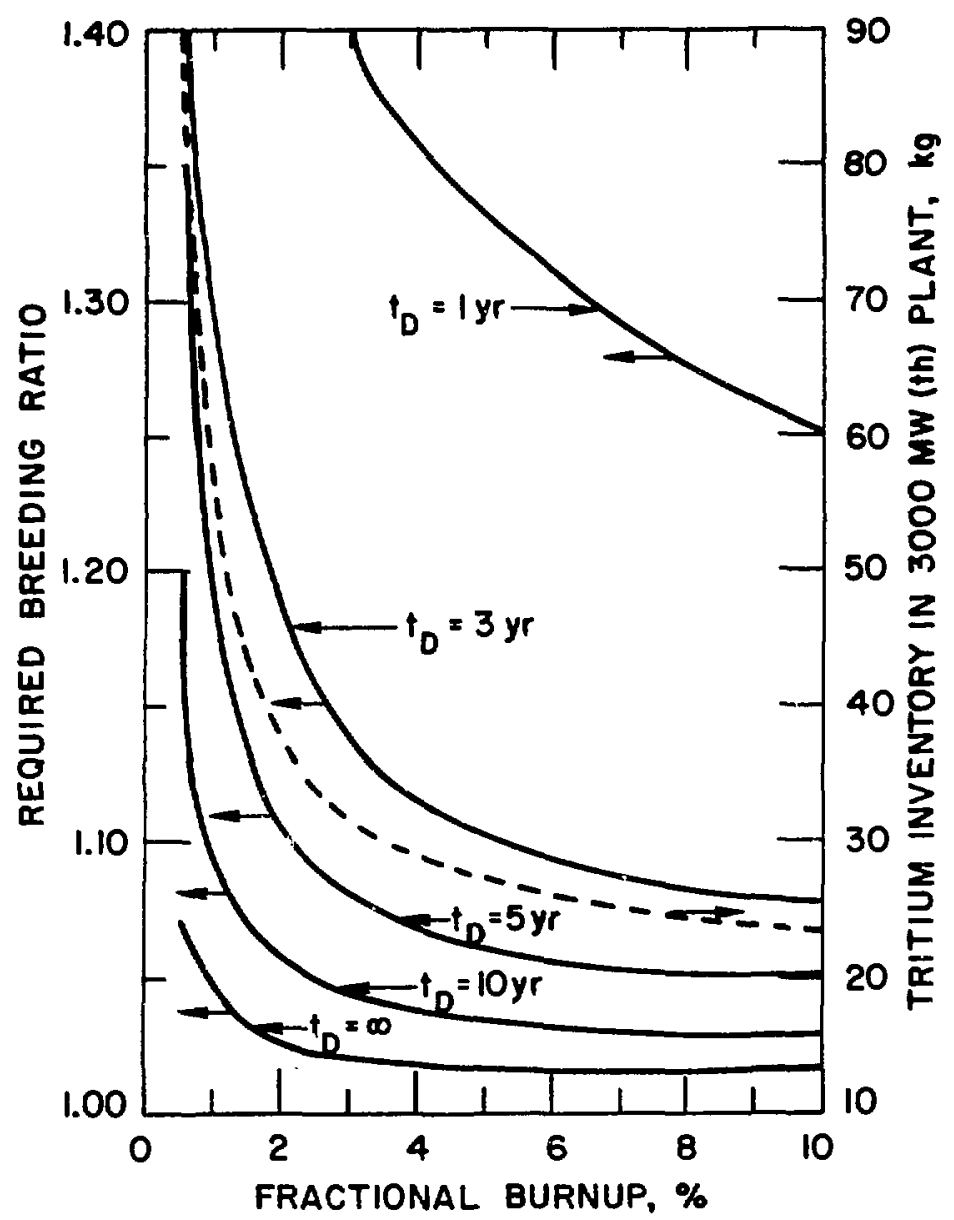

Figure 4. Effect of fractional burnup and doubling time upon required breeding ratio. 
The tritium breeding ratio is sensitive to many of the design features of the fusion reactor. Some of the important features are: 1) the materials, geometry and size of the in-vessel compnnents (e.g., limiter or divertor for impurity control) that intercept the fusson neutrons before entering the blanket; 2) materials, volume fraction and distributions of structural materials and coolants in the first wall and blanket; 3) size and locations of the many void regions that penetrate the blanket and serve important functions such as plasma heating, plasma-current drive, vacuum pumping and fueling; 4) the presence of non-breeding regions in the blanket, which are reserved for presently ill-defined requirements such as passive coils for plasma stabilization; and 5) overall plasma characteristics and reactor configuration, including fusion neutron source distribution, shape of first wall, modularity of components, etc. Fuston is still in a somewhat early stage of research and development with active conceptualization of reactor designs. Technology choices and design concept selections have not been made for many of the reactor systems. These selections will not be made fur a number of years to come because a number of issues are yet to be resolved experimentally and analytically. The achievable tritium breeding ratio is certainly one of the key considerations in the selection among concepts.

The dependence of the tritium breeding ratio on technology and design concept choices can be quite large, $50 \%$ in some instances. Obviously, one cannot design a breeding blanket with a breeding potential that accommodates these large variations. Since the breeding potential for candidate breeding materials will be (and is already being) performed for various technology and design concept choices, we will require that $\mathrm{T}_{\mathrm{D}}$ includes only $2 \%$ allowance for design definition. This is merely enough to account for those add:tional design details that cannot be developed at present for a given conceptual reactor design.

Neutronics calculations of the breeding ratio in a given system are subject to a number of uncertainties. Assuming that the designer uses the best methods and codes available, there are two sources of errors. First, geometrical modeling of the fusion reactor configuration entails some approximations that are necessary to make the problem practical from computer storage and computing-time viewpoints. Second, there are errors that are inherent in all calculational methods and codes for a variety of reasons such 
as those related to numerical techniques, averaging, and/or discrete treatment of continuous variables. Reducing the errors due to calculations to $<2 \%$ appears to be a very difficult goal. ${ }^{9}$

The third source of uncertainty in estimating the breeding ratio comes from errors in nuclear data (e.g., cross sections and energy and angular distribution of secondary neutrons). These include errors arising from the accuracy of measurements, representation of parameters in data files, and processing of the data into a form suitable for use in radiation transport codes. Judging from experience in the fusion program and the estimated sensitivity of $\mathrm{T}$ to variations in nuclear data (discussed later), it is not unreasonable to require accuracles in nuclear data that result $j n$ an error in $T$ of no more than 1 to $2 \%$.

From the above discussions, the allowance $\Delta$ in Fq. 3 required to compensate for a possible shortfall. in tritium breeding due to the combined effects of uncertainties in design definition, calculations, and nuclear data is $\sim 5$ to $6 \%$. Hence, the tritium breeding ratio required in a fusion reactor design must be -1.1 in order for the design concept to have a high potential of achieving self-sustaining DT fusion power economy.

The possibility of operating fusion reactors with a tritiun breeding ratio, $T<1$, by using a tritium concentration in the plasma of $<50 \%$, has been suggested. However, it has been found ${ }^{10}$ that the required magnetic field and reactor size have to be increased rather quickly as $T$ decreases for the same reactor power. Thus, small decrements in $T$ appear very costly in terms of the required plasma performance and the increase in the cost of electricity.

\section{Breeding Potential of Candidate Materials}

As discussed earlier, many blanket design concepts and a number of breeding materials are being considered for fusion reactors. One of the primary selection criteria is achieving an adequate breeding ratio. In this section, we examine the breeding potential of candidate breeding materials.

Based on the discussions in Section 2, the most promising blanket concepts are shown in Table IV. The breeding ratios obtainable with these concepts cover the range of breeding ratios potentially achievable in fusion blankets. There are many possible variations (e.g., hellum instead of water 
coolant) on these designs. However, the four blanket concepts considered in Table IV are sufficient for our purpose here of examining the tritium breeding issues. These concpets were examined in detail in a recent study ${ }^{5}$, and the neutronics calculations performed by Jung are documented in reference 12 .

Table $V$ describes the dimensions and materials used for calculating the breeding ratio for the four blanket options of Table IV. These four designs represent self-consistent choices for the four most promising breeding materials: $\mathrm{Li}, 17 \mathrm{Li}-83 \mathrm{~Pb}, \mathrm{Li}_{2} \mathrm{O}$ and $\mathrm{LiAlO}_{2}$. The neutron transport calculations were performed with the MORSE Monte Carlo code in a 3-D toroidal geonetry (see Figure 5) that models the STARFIRE/DEMO design. A neutron source distribution that accounts for the spatial distribution of the DT reaction rate within the plasma was used. Nuclear data parameters are based on ENDF/BIV. To be consistent with recent experiments, 17-23,47 the $7_{\mathrm{Li}}\left(n, n^{-} \alpha\right) t$ reaction rate was reduced by $15 \%$ for the purpose of calculating the breeding ratio.

The tritium breeding ratio calculated for the four designs are shown in Table VI. These results are for a full blanket coverage, i.e., the first wall/blanket completely circumscribes the plasma with no allowance for penetrations. Thus, the breeding ratios indicated in Table VI represent an upper bound on the breeding potential for the four breeding materials without using a neutron multiplier. Below we discuss design and material variations that can affect $T$, the possibility of using a neutron multiplier, and the breediug characteristics of each breeding material.

\subsection{Effects of Penetrations on $T$}

A variety of penetrations must be accommodated in the blanket system. These can be classified into a) major penetrations, and b) normal penetrations. The major penetrations are large in size and their functional requirements do not permit substantial modifications in their shape. Examples of major penetrations are (see Figure 3): 1) auxiliary heating ducts, presently neutral beams and $\mathrm{rf}$ are the leading contenders; 2) vacuum pumptng ducts; and 3) active impurity control, e.g., a divertor or limiter. Besides being large in number and size, these major penetrations have openings in the first wall in direct visibility to the plasma neutrons. On the other hand, normal penetrations are small or moderate in size, and they are amenable to 
Table IV. Promising Blanket Concepts Under Active Consideration

\begin{tabular}{|c|c|c|c|c|}
\hline \multirow[b]{2}{*}{ Breeder } & \multicolumn{2}{|c|}{ Solid Breeder } & \multicolumn{2}{|c|}{ Liquid Me tal Breeder } \\
\hline & $w_{2} \mathrm{O}$ & $\begin{array}{l}\mathrm{LAIIO}_{2} \\
\left(\mathrm{LH}_{2} \mathrm{~S} \mathrm{SO}_{3}\right)\end{array}$ & Lu & $17: 1-83 \mathrm{~Pb}$ \\
\hline Coolant & $\mathrm{H}_{2} \mathrm{O}$ & $\mathrm{H}_{2} \mathrm{O}$ & $\mathbf{L}$ & $\begin{array}{l}\left(\mathrm{Na}, \mathrm{LI}-\mathrm{Pb}, \mathrm{H}_{2} \mathrm{O}\right) \\
?\end{array}$ \\
\hline Struc ture & SS & ss & $v(F S, S S ?)$ & $\begin{array}{l}\text { v, FS } \\
?\end{array}$ \\
\hline Neutron Multipllet & $?$ & Be & - & - \\
\hline
\end{tabular}

Table V. Description of Four Blanket Designs for Tritium Breeding Calculations

\begin{tabular}{|c|c|c|c|}
\hline Thlckness & $\begin{array}{l}\text { Armor } \\
1 \mathrm{cmll}\end{array}$ & $\begin{array}{l}\text { First Wall } \\
1 \mathrm{~cm}\end{array}$ & $\begin{array}{l}\text { Blanket } \\
68 \mathrm{~cm}\end{array}$ \\
\hline If thium & $\mathrm{FS}^{\mathrm{a}}$ & $357 \mathrm{H}_{2} \mathrm{O}+65 \pi \mathrm{FS}$ & $90 \% \mathrm{Lt}^{*}+10 \mathrm{FS}$ \\
\hline $17 L 1-83 P b$ & FS & $35 \% \mathrm{H}_{2} \mathrm{O}+65 \%$ FS & $85 \% \mathrm{L1}_{17}{ }^{\mathrm{Pb}}{ }_{83}{ }^{* \star}+10 \% \mathrm{FS}+5 \% \mathrm{H}_{2} \mathrm{O}$ \\
\hline $\mathrm{Li}_{2} \mathrm{O}$ & $\mathbf{s s}^{\mathbf{b}}$ & $35 \% \mathrm{H}_{2} \mathrm{O}+65 \% \mathrm{ss}$ & 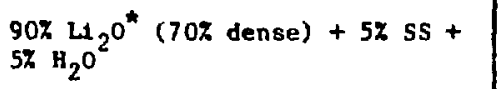 \\
\hline $\mathrm{LiAlO}_{2}$ & ss & $35 \% \mathrm{H}_{2} \mathrm{O}+65 \% \mathrm{SS}$ & $\begin{array}{l}90 \% \mathrm{LAIO}_{2}{ }^{\star \star *}(70 \% \text { desne })+5 \% \text { ss } \\
+5 \% \mathrm{H}_{2} \mathrm{O}\end{array}$ \\
\hline
\end{tabular}

*Natural 11 thium enrichment.

** 907 Lt enrichment.

${ }_{F S}=$ Ferrittc Steel

$b_{\text {SS }}=$ Scalnlesa Steel 


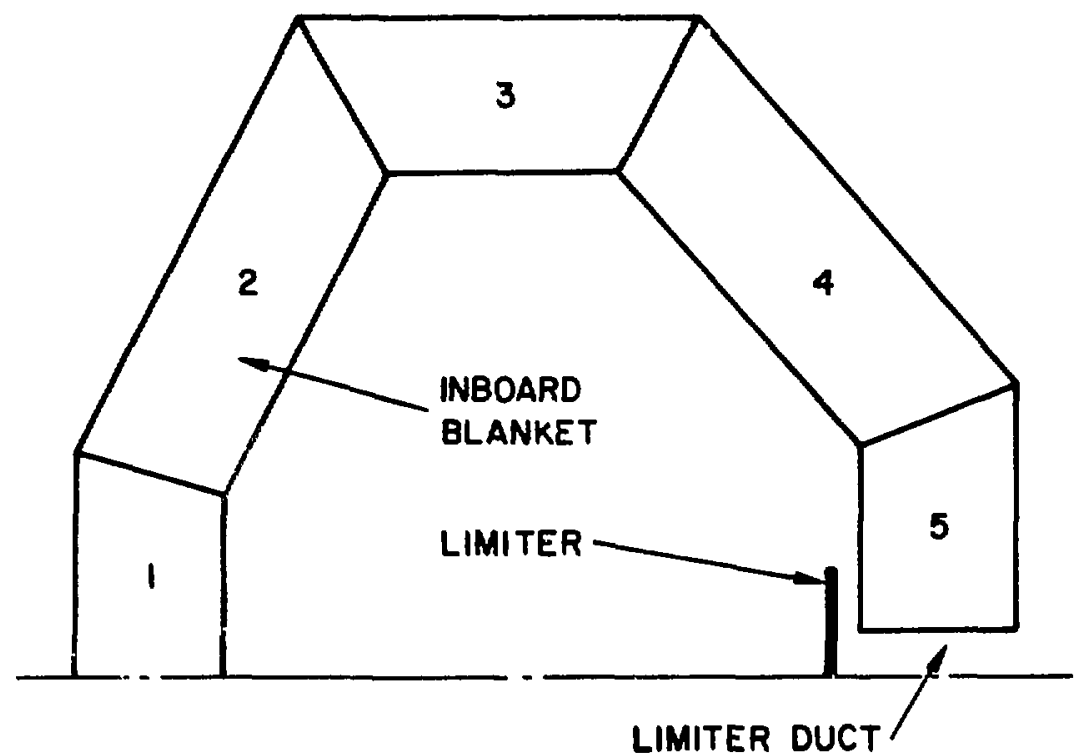

Figure 5. Vertical cross section of the toroidal geometry used for Monte Carlo calculations.

Table VI. Tritium Breeding Ratio Potential (Full breeding blanket coverage with no penetrations.)

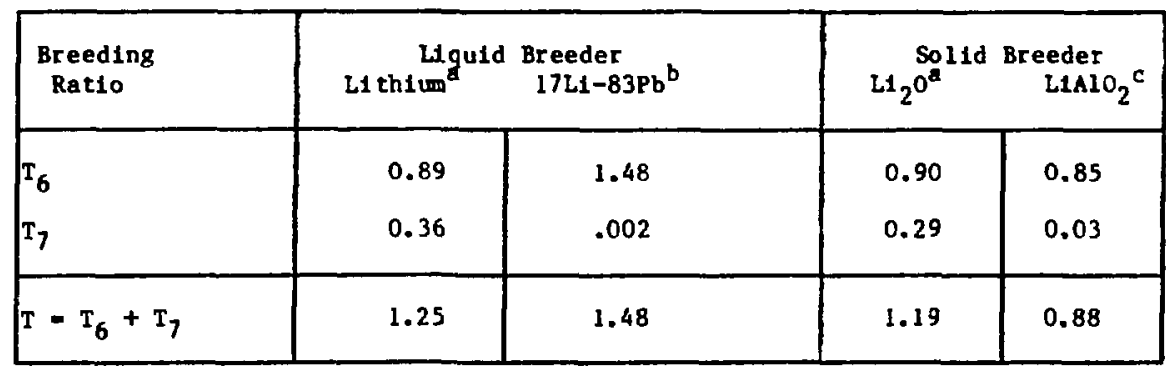

a Natural enrichment.

b90\% ${ }_{6 L}$ enrichment.

$c_{60 \%}{ }^{6} \mathrm{Li}$ enrichent (no neutron mul tiplier). 
substantial shaping of their path inside the blanket and bulk shield. Among the penetrations in this category are the gaps between blanket and shield modules, holes for diagnostics and refueling, and a variety of gaps for clearances around plugs and pipes. For gas-cooled blankets the coolant passages will represent additional radiation streaming paths.

The change of the tritium breeding ratio due to the penetrations, $\Delta T^{P}$, consists of three components: $\Delta T^{S}, \Delta T^{V}$ and $\Delta T^{L}$, due to variation in neutron spectrum, reduction in the volume of breeding zone, and enhanced loss of neutrons, respectively. Radiation streaming enables high energy neutrons to reach deeper regions of the blanket. This tends to increase the ${ }^{7} \mathrm{Li}\left(\mathrm{n}, \mathrm{n}^{-} \alpha\right) \mathrm{t}$ reaction rate. The reduction in the volume of the breeding zone depends strongly on the type of penetration. In recent designs this volume reduction is $\sim 5$ to $10 \%$. The relative reduction in the breeding ratio can be smaller or slightly larger than the relative reduction in the breeding volume, depending on the exact characteristics of the penetrations. Ide et al, 13 showed that the reduction in $\mathrm{T}$ due to the presence of typical neutral beam injectors is $\sim 2 \%$. Jung ${ }^{12}$ estimates a reduction in $\mathrm{T}$ due to the presence of a limiter impurity control system of $\sim 5 \%$. A divertor system ${ }^{14}$ results in a larger reduction in $\mathrm{T}$ than in the case of the limiter.

The reduction in the tritium breeding ratio due to penetrations in a practical power reactor system is > 5\% but does not appear to exceed $10 \%$. This reduction is not overwhelming considering the nature of the major penetrations. However, this reduction can be crucial for breeding materials with a marginal breeding potential.

\subsection{Breeding in the Inboard Blanket}

In magnetic confinement fusion reactors, there are strong incentives for reducing the total thickness of the blanket and bulk shield, $\Delta_{B S}$, to maximize the reactor power for a given magnetic field. In tokamaks, the reactor performance and economics are particularly sensitive to $\Delta_{B S}$ in the inboard region (see figure 3 ). Li thium-containing materials are not very efficient in radiation attenuation. Therefore, it was proposed 16 that the portion of the breeding blanket in the inboard region (i.e., sector 1 in figure 5) be replaced by more efficient shielding materials. Obviously, this is acceptable only if attaining an adequate $T$ is possible without the inboard blanket. 
However, the saving in $\Delta_{B S}$ is so important ${ }^{15}$ that the feasibility of eliminating the breeding blanket from the inboaril region must be considered as a factor in selection of breeding materials. Table VII shows the tritium brerding ratios for the case of when the inboard blanket is eliminated and the limiter impurity control penetration is accounted for. The reduction in the breeding ratio ranges from $\sim 11 \%$ in the $\mathrm{Li}_{2} \mathrm{O}$ case to $\sim 15 \%$ in the $\mathrm{LI}-\mathrm{Pb}$ system. Of this reduction, $-5 \%$ is due to the $11 \mathrm{miter}$ and the balance is due to elimination of the inboard blanket.

\subsection{Past and Thermal Systens}

Blanket concepts can be generally classified into "fast" and "thermal" systeins. In the fast system, high energy neutrons in the 4 to $15 \mathrm{MeV}$ range contribute significantly to breeding via the ${ }^{7} \operatorname{Li}\left(n, n^{-} \alpha\right) t$ reaction. In the thermal system, neutrons are slowed down by elements other than ${ }^{7} \mathrm{Li}$ (before or at ter entering the breeding material region) so that essentially all the tritium breeding is achieved by low energy neutrons, inducing the reaction ${ }^{6} \operatorname{Li}(n, \alpha) t$.

Of the four systems considered in Tables $V$ and $V I, ~ l i$ thium and $\mathrm{LI}_{2} \mathrm{O}$ represent a "fast" system, while $17 \mathrm{LI}-83 \mathrm{~Pb}$ and $\mathrm{LiAlO}_{2}$ are representative of a thermal" system. Figures 6 and 7 show typical neutron spectra in both types of blanket. The neutron moderating power of lithlum is not very strong. Therefore, the high energy neutrons penetrate into the deeper regions of the blanket, resulting in a significant ${ }^{7} L\left(n, n^{-} \alpha\right) t$ reaction rate. In a liquid I i thium blanke $\mathrm{C}_{,} \mathrm{T}_{i}$ is $-30 \%$ of $\mathrm{T}$. Therefore, the relative error in $\mathrm{T}$ is approximately one-third of the relative error in the magnitude of the ${ }^{7} \mathrm{LI}\left(\mathrm{n}, \mathrm{n}^{\circ} \alpha\right) \mathrm{t}$ reaction cross section. The contribution of ${ }^{7} \mathrm{LI}$ to the tritium breeding ratio in $\mathrm{Li}_{2} \mathrm{O}$ is $\sim 24 \%$. The reduction of $\mathrm{T}_{7}$ in $\mathrm{Li}_{2} \mathrm{O}$ relative to that in $L i$ is due to scattering of high energy neutrons with oxygen in the $\mathrm{L}_{2}{ }_{2} \mathrm{O}$ and the water coolant.

In the absence of a neutron multiplier, the contribution of ${ }^{7} \mathrm{Li}$ is an absolute necessity to achieve $\mathrm{T}>1$ in $\mathrm{LI}$ and $\mathrm{LI}_{2} \mathrm{O}$. Studies have shown that the natural isotopic composition of 11 thium $\left(92.5 \%{ }^{7} \mathrm{Li}\right.$ and $\left.7.5 \%{ }^{6} \mathrm{Li}\right)$ yields nearly optimum breeding ratio with no benefit from enrichment in ${ }^{6}$ Li. If a neutrun multiplier is incorporated in $\mathrm{Li}$ and $\mathrm{Li}_{2} \mathrm{O}$ blankets, the neutronics characteristics of these fast systems change to those of a thermal system. 
Table VII. Tritium Breeding Ratio with and without Inboard Blanket and Limiter

\begin{tabular}{|c|c|c|c|c|}
\hline & $\begin{array}{r}\text { Liqui } \\
\text { Lithiuma }\end{array}$ & $\begin{array}{l}\text { Breeder } \\
\quad 17 \mathrm{LI}-\mathrm{B} 3 \mathrm{~Pb}\end{array}$ & $\mathrm{L1}_{2} \mathrm{O}^{\mathrm{B}}$ & $\begin{array}{l}\text { Breeder } \\
\mathrm{LAIO}_{2} \mathrm{c}\end{array}$ \\
\hline $\begin{array}{l}\text { Full Blanket Coverage, } \\
\text { No Penetrations } \\
\text { No Inboard Blanket, } \\
\text { I. Imiter Penetration } \\
\text { Included }\end{array}$ & $\begin{array}{l}1.25 \\
1.09\end{array}$ & $\begin{array}{l}1.48 \\
1.26\end{array}$ & $\begin{array}{l}1.19 \\
1.06\end{array}$ & 0.88 \\
\hline
\end{tabular}

a Natural enrlchment.

$b_{90 \%}{ }_{1 L}$ entichment.

${ }_{60 \%}^{6}{ }^{6}$ l enrichrent (no neutron multiplier).

\section{NEUTRON SPECTRUM}

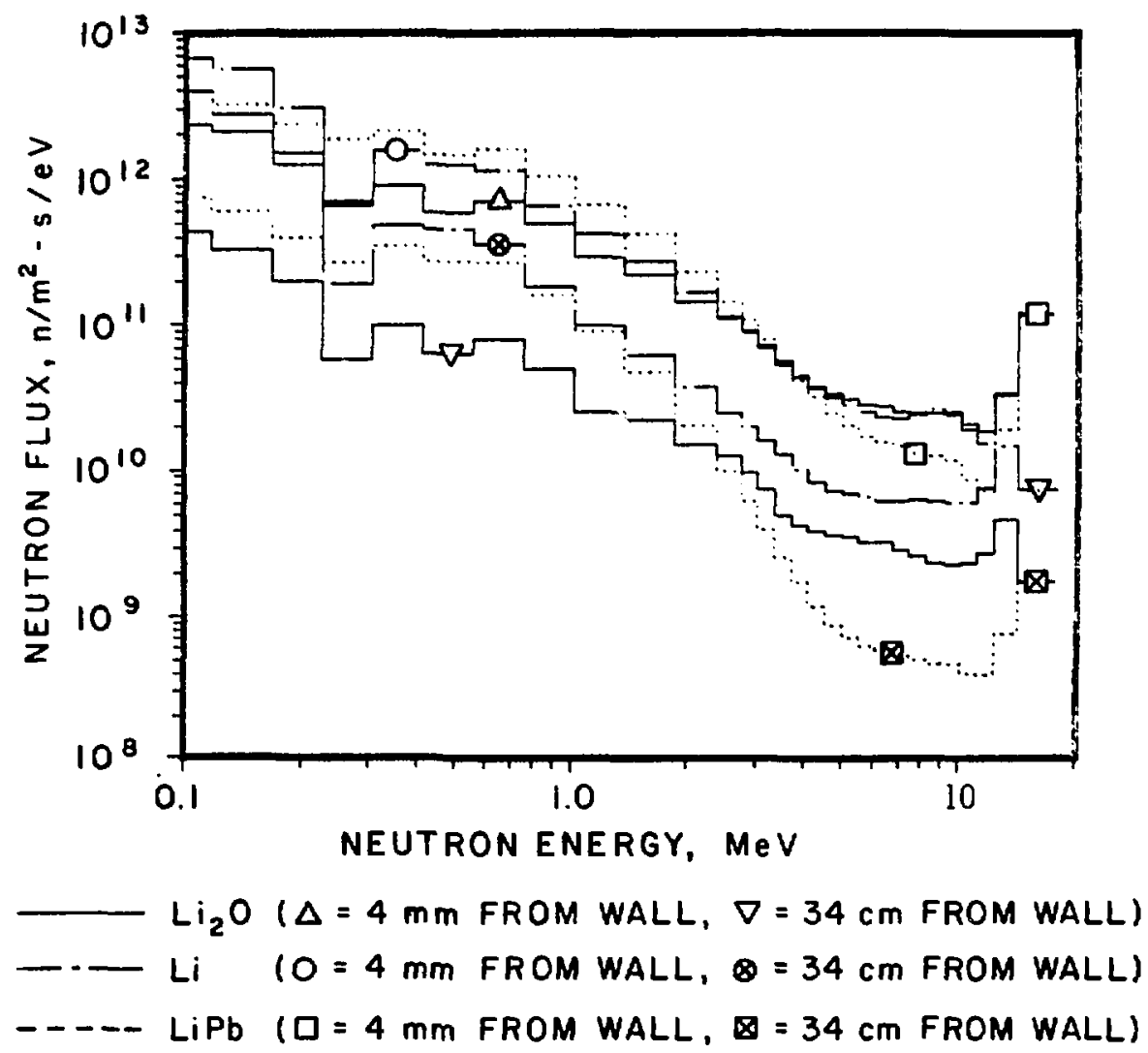

Figure 6a. Neutron spectrum in three blanket systems: $\mathrm{Li}_{2} \mathrm{O}, \mathrm{Li}$ and $17 \mathrm{Li}-83 \mathrm{~Pb}$. The systems are described in Table v. (Energy range $10^{-1}-15 \mathrm{eV}$. 


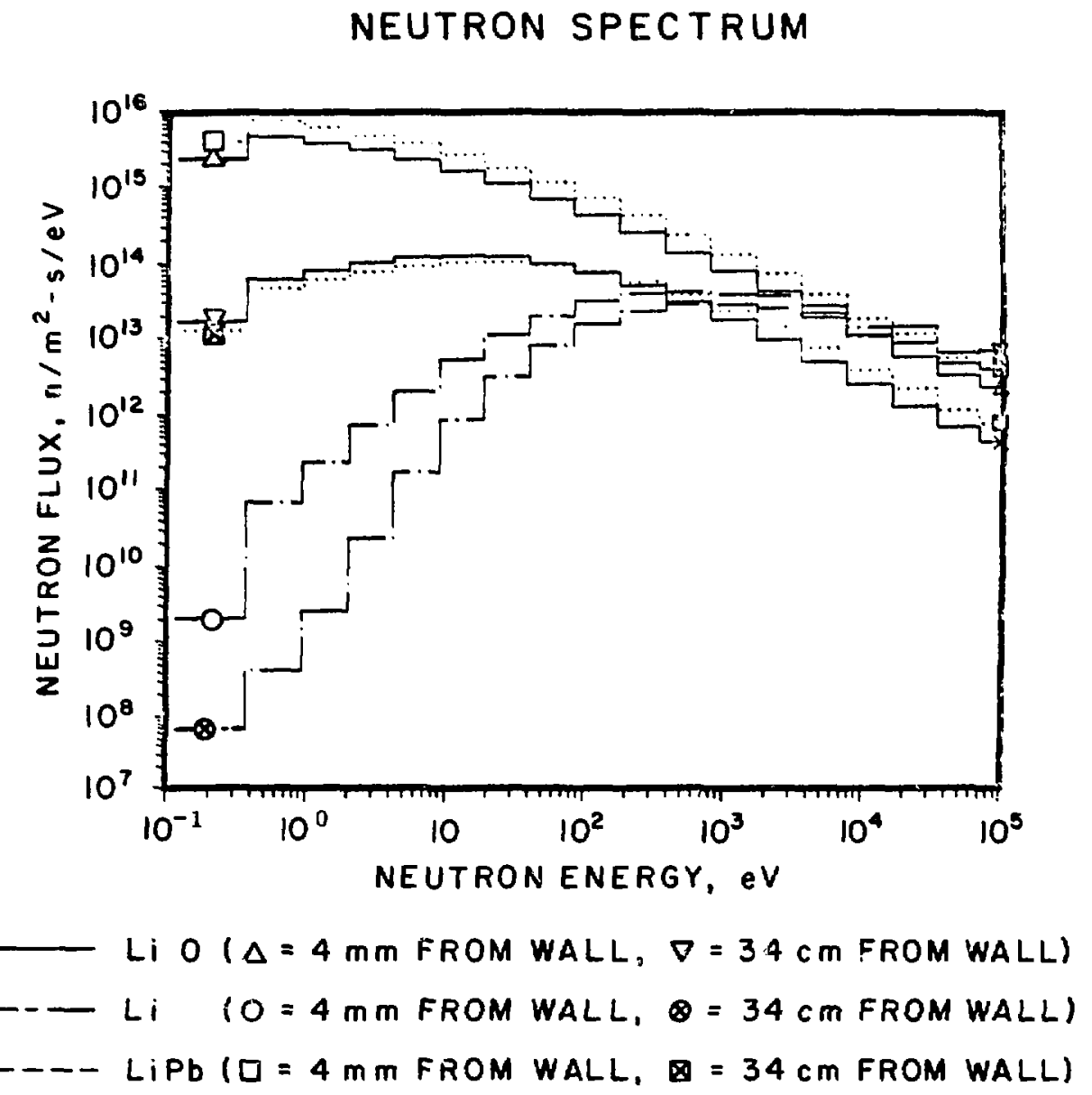

Figure 6b. Neutron spectrum in three blanket systems: $\mathrm{Li}_{2} \mathrm{O}, \mathrm{Li}$ and $17 \mathrm{Li}-83 \mathrm{~Pb}$. The systems are described in Table $\mathrm{V}$. (Energy range $10^{-1}-10^{5} \mathrm{eV}$. ) 


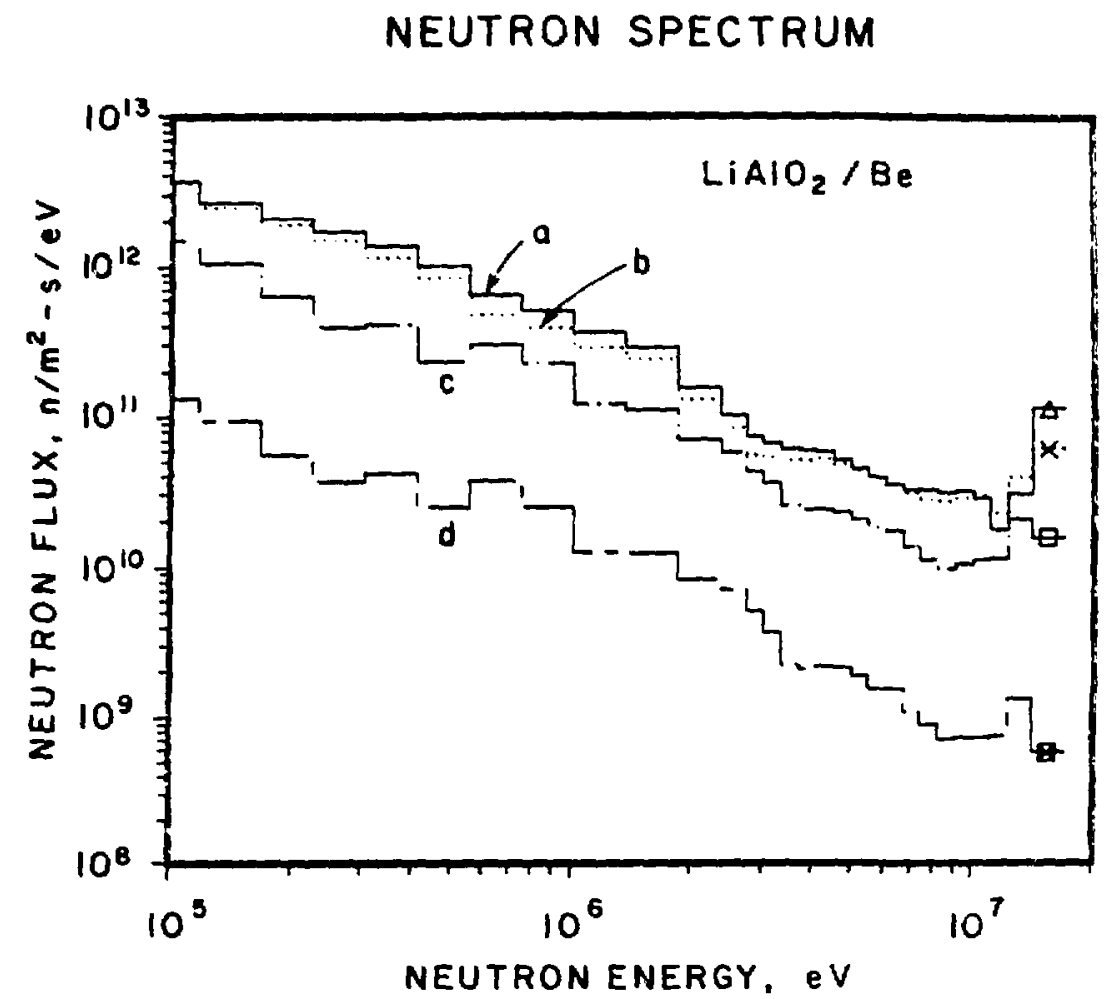

Figure 7a. Neutron spectrum in $\mathrm{LiAlO}_{2}$ blanket with beryllium multiplier. The system consists of $1 \mathrm{~cm}$ first wall (Zone 1 ), $4 \mathrm{~cm} \mathrm{LiAlO} 2$ (Zone 2), $8 \mathrm{~cm} \mathrm{Be}$ (Zone 3), $20 \mathrm{~cm} \mathrm{LiAl02} \mathrm{(Zone} \mathrm{4).} \mathrm{Curves} \mathrm{a}$ and $b$ are for the first and last points, respectively, in Zone 2. Curves $c$ and $d$ are for the first and midpoint of Zone 4. (Energy range 0.1 - $15 \mathrm{MeV}$.) 


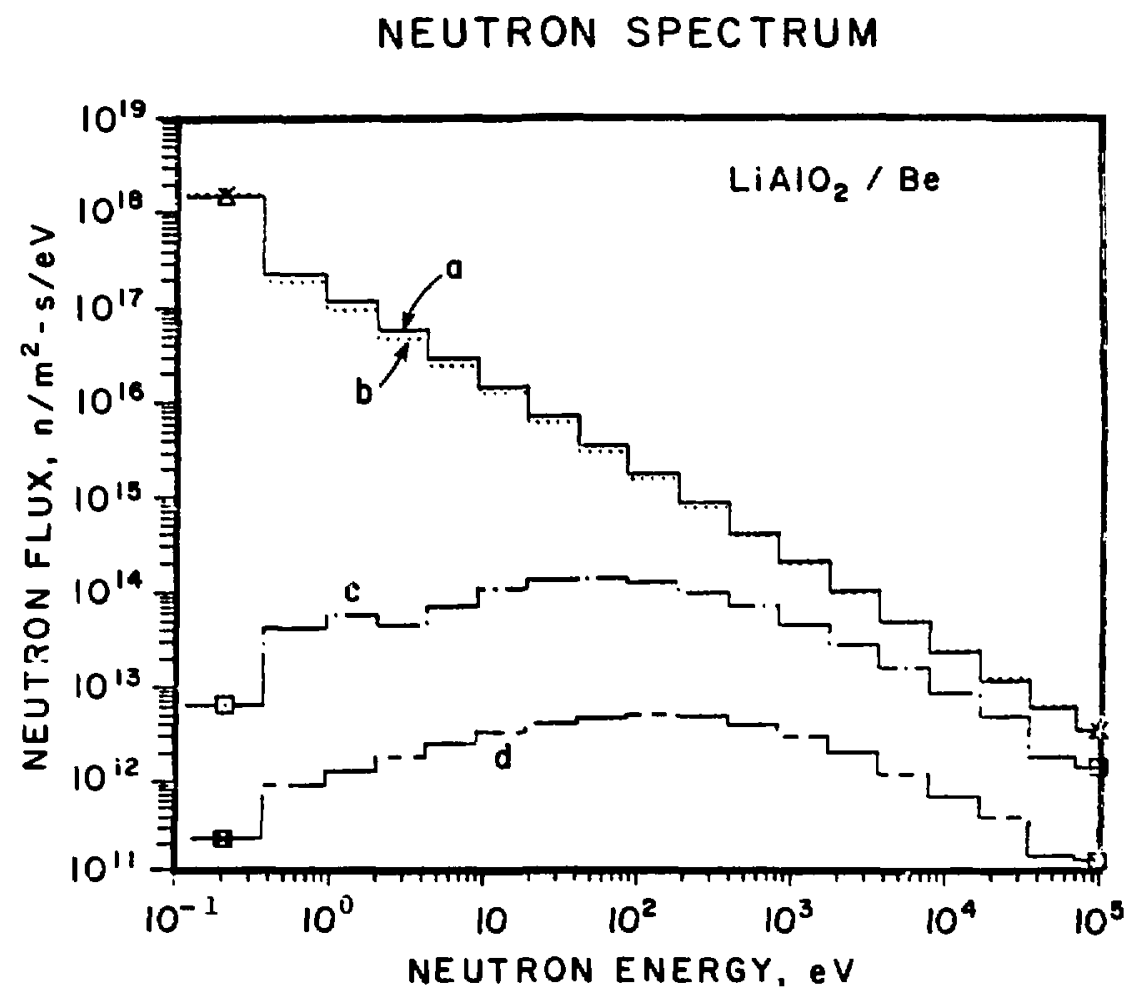

Figure 7b. Neutron spectrum in $\mathrm{LiAlO}_{2}$ blanket with beryllium multiflier. The system consists of $1 \mathrm{~cm}$ first wall (Zone 1), $4 \mathrm{~cm} \mathrm{LiAlO}_{2}$ (Zone 2), $8 \mathrm{~cm} \mathrm{Be} \mathrm{(Zone} \mathrm{3),} 20 \mathrm{~cm} \mathrm{LiAlO} 2$ (Zone 4). Curves $a$ and $b$ are for the first and last points, respectively, in Zone 2. Curves $c$ and $d$ are for the first and midpoint of Zone 4. (Energy range $10^{-1}-10^{5} \mathrm{eV}$. ) 
The in-rease in the $(n, 2 n)$ reaction rate in the neutron multiplier is always associated with a reduction in the ${ }^{7} \mathrm{LI}\left(n, n^{-} \alpha\right) t$ reaction rate. Thus the enhancement of $\mathrm{T}$ by using a neutron multiplier tends to be modest for the $\mathrm{LI}$ and $\mathrm{Li}_{2} \mathrm{O}$ systems as will be discussed shortly.

Liquid $17 \mathrm{Li}-83 \mathrm{~Pb}$ has one of the highest breeding potentials because of the large neutron multiplication in the breeding material itself through the $\mathrm{Pb}(n, 2 n)$ and $(n, 3 n)$ reactions. The ${ }^{7} \mathrm{Li}\left(n, n^{-} \alpha\right) t$ reaction rate is reduced to an insignificant contribution (see Table VI) due to the rapid slowing down of high energy neutrons by inelastic scattering in $\mathrm{Pb}$. Flowever, the neutron multiplication via the $\mathrm{Pb}(n, 2 n)$ is large enough to result in a $T_{6}$ that is much greater than the breeding ratio achievable in the $\mathrm{Li}$ and $\mathrm{Li}_{2} \mathrm{O}$ systems. Since the number density of 11 thium in Li-Pb is very low (about an order of magnitude lower than $\mathrm{In} \mathrm{Li}$ and $\mathrm{Li}_{2} \mathrm{O}$ ), isotopic enrichment of ${ }^{6} \mathrm{Li}$ is crucial to attaining a high tritium breeding ratio. The lithium in the Li-Ph system used in Tables V-VII is enriched to $90 \%{ }^{6} \mathrm{Li}$. Most of tritium breeding comes from neutrons in the low eV range. The soft spectrum that prevails in such a thermal system requires particular care in the neutronics treatment. This system also is more sensitive to the amount and type of structural material and coolant used.

The tritium breeding characteristics are similar for blankets using the ternary ceramics such as $\mathrm{LiAlO}_{2}, \mathrm{Li}_{2} \mathrm{SiO}_{3}, \mathrm{Li}_{2} \mathrm{ZrO}_{3}$ and $\mathrm{Li}_{2} \mathrm{TiO}_{3}$. The strong neutron moderation by the non-lithium elements renders ${ }^{7} \mathrm{Li}$ useless for tritium production (see Table VI). In the absence of a neutron multiplier, $T$ is always < 1 for these ceramic breeders. Hence, the viability of solid breeders (other than $\mathrm{Li}_{2} \mathrm{O}$ ) from tritium breeding viewpoint is unavoidably dependent on the ability to use a neutron multiplier.

\subsection{Neutron Multipliers}

Enhancing the tritium production capability of the blanket by incorporating a neutron multiplier has been examined in a number of design studies. The subject has been treated in some detail in references $4,5,12$, 24,25 and 27 . The results of these studies are surprising. Finding an acceptable neutron multiplier appears to be extremely difficult. 
Table VIII lists the candidate neutron multipliers and presents some of the key properties relevant to their utilization in fusion blankets. Fissionable materials are excluded since hybrid concepts are not presently included in the main-line fusion development.

A good neutron multiplier must have a large $(n, 2 n)$ and/or $(n, 3 n)$ cross section, with a threshold much lower than $10 \mathrm{MeV}$. It must also have a relatively small parasitic absorption over the entire energy range of 0 to 15 MeV. It is desirable that the inelastic cross section be relatively small. Lead, bismuth and zirconium appear to be the only high-z materials that are potentially useful neutron multipliers. Compounds such as PbO, PbBI and $\mathrm{Zr}_{5} \mathrm{Ph}_{3}$ need to be considered for engineering reasons. Low-Z materials typically have low $(n, 2 n)$ cross sections with the well-known exception of beryllium.

In order to select a material for any component of the blanket it must satisfy a number of engineering criteria in addition to possessing acceptable neutronics characteristics. Some of these engineering criteria are availability, cost, fabricability, and compatibility with coolant and s truc ture.

Lead and bismuth have the most attractive neutronics characteristics excent for beryllium. Zirconium has an $(n, 2 n)$ cross section that is about a factor of 3 lower than that for $\mathrm{Pb}$ and $\mathrm{Bl}$. The key engineering problem for lead and bismuth is their low melting point ( 327 and $271^{\circ} \mathrm{C}$, respectively). To keep the material solid during reactor operation, $i$ ts melting point must be higher than the coolant temperature. The exit temperature for a hellum coolant is typically $>450^{\circ} \mathrm{C}$. The lowest operating temperature in a blanket design is achievable with pressurized water, which ylelds an acceptable thermal conversion effictency with a maximum temperature of $\sim 320^{\circ} \mathrm{C}$. Thus, the use of lead and bismuch in solid form in fusion power reactors is not practical. For near-term experimental reactors such as INTOR, ${ }^{14,25}$ power conversion is not an objective and the maximum coolant temperature is $100^{\circ} \mathrm{C}$. In this case, lead or bismuth can be used in solid form. However, the poor thermal conductivity of lead limits the maximum thickness of the neutron multiplier zone to $\sim 5 \mathrm{~cm}$ for a neutron wall load of $\sim 1 \mathrm{MW} / \mathrm{m}^{2}$. The allowable 
Table VIII. Properties of Candidate Neutron Multiplier Materials

\begin{tabular}{|c|c|c|c|c|c|c|c|}
\hline Ma ter $1 a 1$ & Re & BeO & $\mathrm{Pb}$ & Pbo & B1 & $\mathrm{Zr}_{5} \mathrm{~Pb}_{3}$ & PbB1 \\
\hline Dens $1 \mathrm{cy}, \mathrm{g} / \mathrm{cm}^{3}$ & 1.85 & 2.96 & 11.34 & 9.53 & 9.8 & 8.93 & 10.46 \\
\hline A tom or molectules/ & 0.1236 & 0.07127 & 0.03348 & 0.02571 & 0.02824 & 0.004680 & 0.03047 \\
\hline$\underset{\text { barns }}{\sigma(n, 2 n)}$ at $14 \mathrm{MeV}$, & 0.5 & 0.5 & 2.2 & 2.2 & 2.2 & 9.2 & 2.2 \\
\hline$\underset{\mathrm{cm}}{\Sigma\left(n_{2}, 2 n\right)}$ at $14 \mathrm{MeV}, \mathrm{cm}$ & 0.0618 & 0.256 & 0.0737 & 0.0565 & 0.0621 & 0.0431 & 0.0670 \\
\hline$(n, 2 n)$ threshold, MeV & 1.868 & 1.868 & 6.765 & 6.675 & 7.442 & 6.765 & 6.765 \\
\hline $\begin{array}{c}\sigma(n, \gamma) \text { at } 0.0253 \mathrm{ev}, \\
\text { barns }\end{array}$ & 0.0095 & 0.0095 & 0.17 & 0.17 & 0.034 & 1.41 & 0.094 \\
\hline Radtoactiv1 ty & & & & & & & \\
\hline Isotopes & $10_{\mathrm{Be}}$ & $10_{\mathrm{Be}}$ & ${ }^{205} \mathrm{~Pb}$ & ${ }^{205} \mathrm{pb}$ & $210_{\text {Po }}$ & ${ }^{93} \mathrm{zr},{ }^{205} \mathrm{~Pb}$ & ${ }^{205} \mathrm{~Pb},{ }^{210} \mathrm{Po}$ \\
\hline Me1ting point, ${ }^{\circ} \mathrm{C}$ & 1278 & 2520 & 327.5 & 888 & 271.3 & 1400 & 125 \\
\hline$\left\{\begin{array}{c}\text { Thermal Conductivity } \\
\text { at } 25^{\circ} \mathrm{C}, \mathrm{H} / \mathrm{m}-{ }^{\circ} \mathrm{K}\end{array}\right.$ & 201 & $216^{b}$ & 35.3 & 2.8 & $7.92^{c}$ & - & $2.3^{d}$ \\
\hline
\end{tabular}

a At $25^{\circ} \mathrm{C}$.

Pure beryllium oxide, hot pressed.

CPolycrystalline.

det $200^{\circ} \mathrm{C}$. 
thickness is even smaller for bismuth. It should be noted that the significant production of the $\alpha$-emitter $21{ }^{2}$ Po makes bismuth an undesirable material in a power reactor system.

The only practical possibility for using lead or bismuth in a fusion power reactor blanket is in liquid form. However, liquid lead and bismuth are not compatible with candidate structural materials. To limit corrosion of stainless steel, a maximum operating temperature of $\sim 450^{\circ} \mathrm{C}$ has to be imposed. With such temperature limit and at a nuetron wall load of $\sim 3 \mathrm{MW} / \mathrm{m}^{2}$, the low thermal conductivity of lead limits the maximum spacing between coolant tubes to $\sim 2 \mathrm{~cm}$. This reduces considerably the benefits of lead as a neutron multiplier because of the parasitic neutron absorption in the coolant structure. The situation is even less attractive for bismuth and PbBi. Jead oxide has a much higher melting point $\left(888^{\circ} \mathrm{C}\right)$. However, its lower thermal conductivity and the presence of oxygen make $\mathrm{PbO}$ 1nferior to lead as a neutron mul tiplier.

The intermetallic compound $\mathrm{Zr}_{5} \mathrm{~Pb}_{3}$ was considered in the STARFIRE study because it has a higher melting point $\left(\sim 1400^{\circ} \mathrm{C}\right)$ than lead and a greater neutron multiplication than zirconium. However, as we will show shortly, the breeding enhancement achievable with $\mathrm{Zr}_{5} \mathrm{~Pb}_{3}$ is not great.

Beryllium is very attractive neutronically because its $(n, 2 n)$ cross section is large over a wide energy range $(\sim 2$ to $15 \mathrm{MeV})$ and its parasitic neutron absorption is small. There are two serious issues in using berylliun in fusion reactors. The first is the limited known resources of beryllium. The estimated reserves for beryllium are $2.5 \times 10^{7} \mathrm{~kg}$ in the U.S. and $\sim 3.8 \times$ $10^{8} \mathrm{~kg}$ in the world. A 5-cm-thick beryllium zone in a typical tokamak power reactor require $\sim 7 \times 10^{4} \mathrm{~kg}$ of beryllium, $1 . e ., \sim 0.3 \%$ of the U.S. reserves. Thus, beryllium reserves cannot surtain a full fusion power economy. However, the beryllium burnup over the reactor life $(\sim 40 \mathrm{y})$ is $10 \%$. Assuming recycling of beryllium is feasible, beryllium can be used in tens of fusion reactors without exhausting a significant fraction of beryllium reserves. The second serious issue is that beryllium is toxic. This toxicity makes beryllium difficult to handle and introduces additional factors into safety and environmental considerations for fusion reactors. The cost of beryllium is high, but this is more than offset by its excellent additional energy multiplication. Helium generation rate in beryllium is extremely 
large, typically $\sim 8000 \mathrm{appm} / \mathrm{yr}$ in a power reactor. This requires using beryllium at only $\sim 60$ to $70 \%$ of its theoretical density in order to accommodate swelling. This requirement increases the effective fraction of structural mateiral and reduces slightly the net neutron multiplication benefit. The $\operatorname{Be}(n, t)$ reaction with a threshold of $11.6 \mathrm{MeV}$ and a cross section of $\sim 20 \mathrm{mb}$ at $14 \mathrm{MeV}$ resuls in a significant tritium production. The tritium inventory trapped in beryllium is a cause for concern. This inventory is estimated ${ }^{12}$ to be in the range of 2 to $3 \mathrm{~kg}$ after five years of operation at $3 \mathrm{MW} / \mathrm{m}^{2}$ neutron wall load in a typical power reactor.

Gohar 24,4 examined the effect of various neutron multipliers on the tritium breeding ratio in a blanket that uses $\mathrm{LiAlO}_{2}$ as a breeding material. He performed one-dimensional calculations using the first wall/blanket composition shown in Table IX. A neutron multiplier zone was used behind the first wall and preceeding the breeding material region. The coolant and structure were homogenized with the neutron multiplier. Figure 8 shows the tritium breeding ratio as a function of the neutron multiplier zone thickness for a number of neutron multipliers. A few important observations can be made on the results in this figure. The breeding $r$ tio shows a maximum at a multiplier zone thickness of $\sim 5$ to $8 \mathrm{~cm}$. The reason is that as the multiplier thickness increases the $(n, 2 n)$ reaction rate increases but a larger fraction of the neutrons is thermalized and absorbed in the structure before reaching $\mathrm{LiAlO}_{2}$. While Figure 8 indicates a comparable neutronics performance for lead and beryllium, it must be realized that the practicality of the lead system is questionable as discussed above. The very severe limitations on the spacing between coolant channels for lead will substantially degrade the obtainable breeding ratio to much lower values than those indicated in Figure 8. The maximum one-dimensional breeding ratio shown in Figure 8 for blankets with $\mathrm{Be}$ and $\mathrm{Pb}$ is 1.18, which is lower than that obtainable for $\mathrm{Li}$ and $\mathrm{Li}_{2} \mathrm{O}$ wi thout a neutron multiplier.

Beryllium has been shown ${ }^{12}$ to be the only non-fissionable neutron multiplier capable of significantly increasing the breeding ratio in lithium and lithium-oxide blankets. (Using lead in a Li-Pb compound results in high $T$ as discussed earlier but such concept is classified in another category.) The neutron multiplier can be incorporated in the blanket in a number of possible 
Table IX. Blanket Parameters for Internally-Cooled Neutron Multiplier Concepts

\begin{tabular}{|c|c|c|}
\hline Zone Description & $\begin{array}{c}\text { Zone Th1 ckness } \\
\text { ca }\end{array}$ & $\begin{array}{c}\text { Zone Composition, Vol. } \\
\text { Internally-Cooled }\end{array}$ \\
\hline F158t Wall & 1 & $\begin{array}{ll}50 Z & \mathrm{PCA} \\
50 \mathrm{Z} & \mathrm{H}_{2} \mathrm{O}\end{array}$ \\
\hline Neutron Multiplier & Variable & $\begin{array}{l}\text { 85\% neutron aultiplier } \\
10 \% \text { PCA } \\
5 \% \mathrm{H}_{2} \mathrm{O}\end{array}$ \\
\hline Tritiun Breeder & 50 & $\begin{array}{rl}80 \% & \mathrm{LAAlO}_{2} \text { breeder } \\
10 \% & \mathrm{PCA} \\
5 \% & \mathrm{H}_{2} \mathrm{O} \\
5 \% & \mathrm{He} \text { purge }\end{array}$ \\
\hline Reflectis & 15 & $\begin{array}{ll}50 \% & \text { carbon } \\
25 \% & \mathrm{PCA} \\
25 \% & \mathrm{H}_{2} \mathrm{O}\end{array}$ \\
\hline
\end{tabular}

${ }_{90 \%}{ }^{6} \mathrm{~L}$.

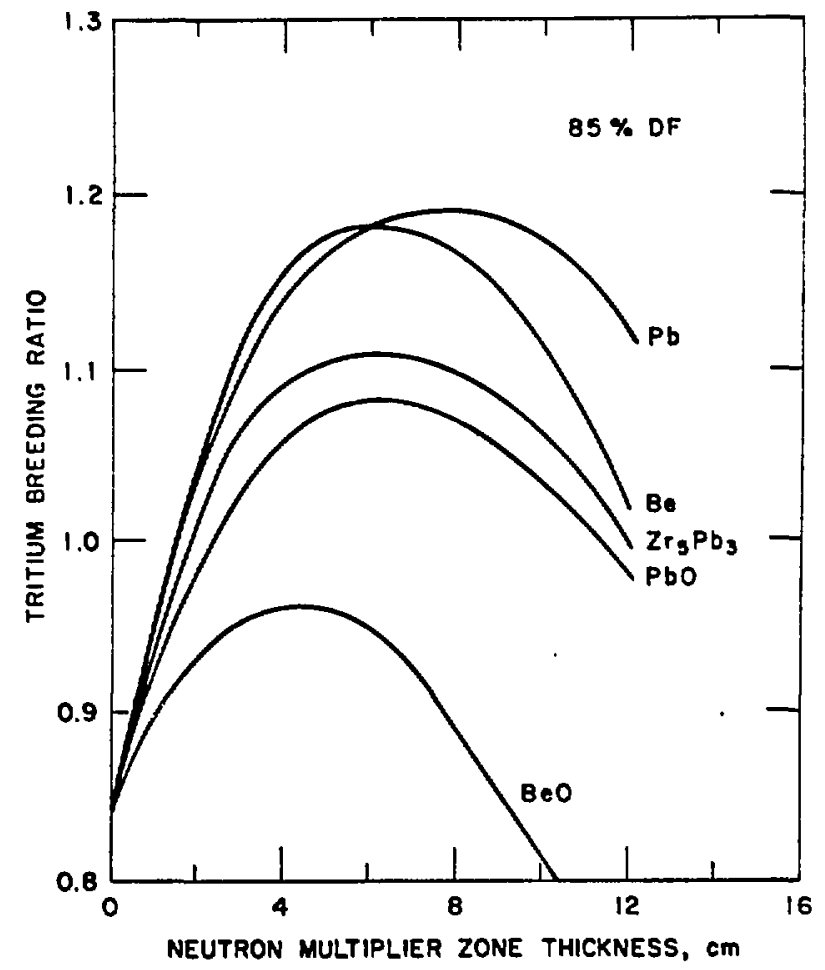

Figure 8. Tritium breeding ratio from the separate zone blanket option with different neutron multipliers (internally cooled) with $\mathrm{LiAlO}_{2}\left(90 \% 6_{\mathrm{Li}}\right)$ breeder, $\mathrm{H}_{2} \mathrm{O}$ coolant and PCA structure. 
arrangements as illustrated in Figure 9. Optimum use of beryllium appears to be not immediately behind the first wall. but behind several centimeters of $\mathrm{Li}$. or $\mathrm{Li}_{2} \mathrm{O}$, particularly for a thick $(1-2 \mathrm{~cm})$ first wall.

\subsection{Conclusions on Breeding Potential}

In a previous section, we Indicated that the tritium breeding ratio required in an operating reactor is

$$
\mathrm{T}_{0} \sim 1.05
$$

We also indicated that present uncertainties in design definition, calculational methods, and nuclear data make it necessary to demand that prudent designs of fusion blankets performed at present should require that the design be capable of yielding a breeding ratio

$$
\mathrm{T}_{\mathrm{D}} \sim 1.1
$$

Breeding materials and design concepts that are limited to $\mathrm{T}<\mathrm{T}_{0}$ should be rejected. In addition, if their maximum predicted breeding ratio $\left(T_{m}\right)$ is such that $T_{0}<T_{m}<T_{D}$, the development of these materials and concepts will entail a high risk of not achieving the tritium breeding requirement. It should not be inferred that the success of those materials and concepts that are now predicted to yield a breeding ratio slightly higher than $T_{D}$ is guaranteed.

A large number of tritium breeding studies have heen performed over the past 15 years. The most recent of these were summarized in this section. These studies are not exhaustive. However, they do permit a judgement on the $\mathrm{T}_{\mathrm{m}}$ that can probably be achieved with each breeding material in a fusion power reactor. This judgement is based on all the neutronics, engineering, technology, and economics considerations known to us today. However, this judgement cannot now be conclusive and may have to be revised in the future if dramatic changes occur in fusion reactor designs.

Table $X$ shows the estimated $T_{m}$ achievable with present designs for liquid lithiuin, $\mathrm{Li}_{17} \mathrm{~Pb}_{83}, \mathrm{Li}_{2} \mathrm{O}$ and $\mathrm{LiAlO}_{2}$. The highest breeding potential is offered by $\mathrm{Li}_{17} \mathrm{~Pb}_{83}$ wit a $\mathrm{T}_{\mathrm{m}}$ of $\sim 1.3$. This margin is large enough to judge tritium breeding feasibility with $\mathrm{LI}_{17} \mathrm{~Pb}_{83}$ to be certain. $\mathrm{T}_{\mathrm{m}}$ for $\mathrm{Li}$ and $\mathrm{LI}_{2} \mathrm{O}$ is 1.15 

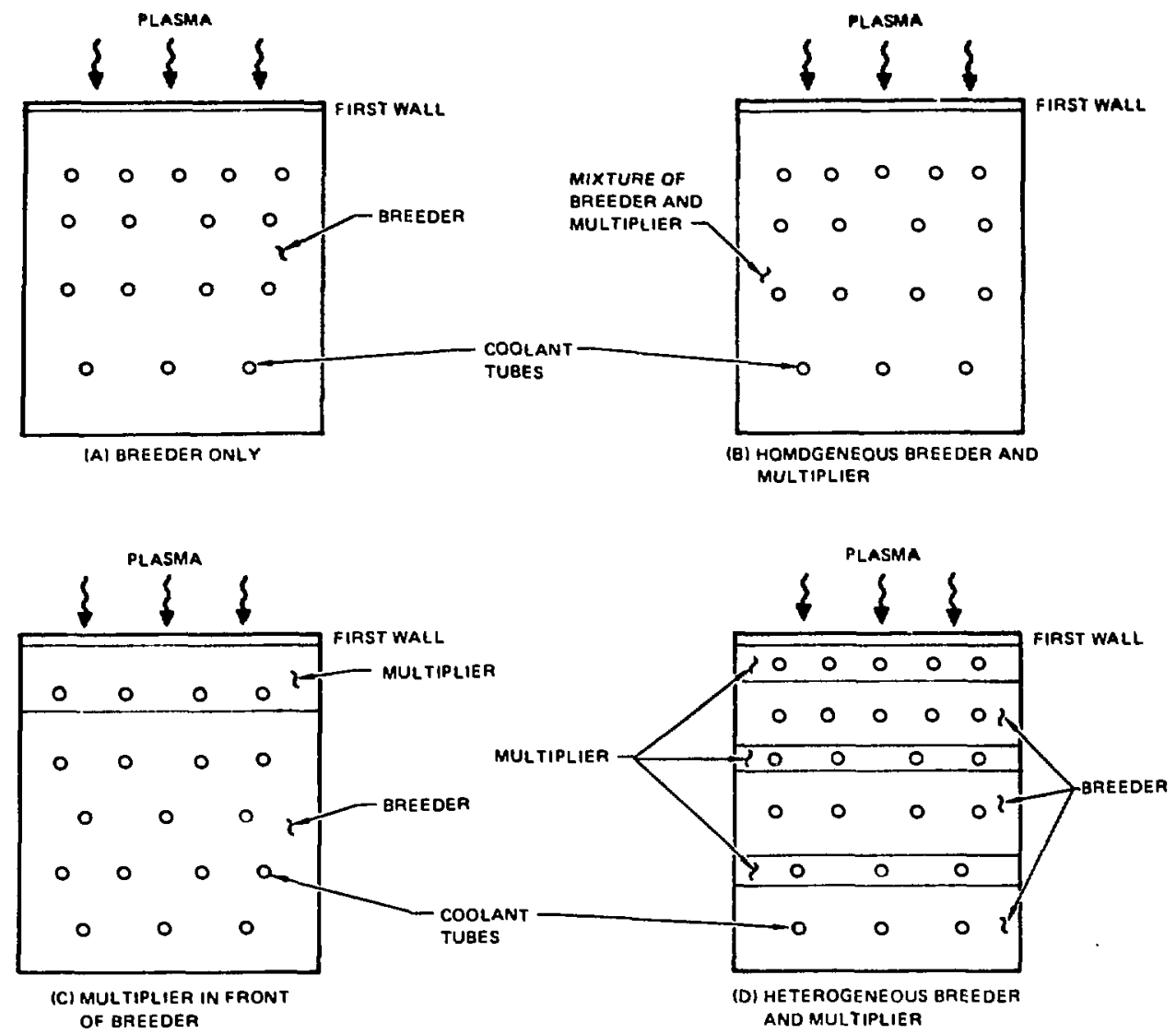

Fig. 9. Possible arrangements of solfd breeder \& solid neutron multiplier.

Table X. Estimated Tritium Breeding Ratio Likely to be Achievable in Fusion Power Reactors

\begin{tabular}{|c|c|c|}
\hline Breeding Material & Breeding Ratio & Comment \\
\hline Liquid Li thium & 1.15 & Low Risk \\
\hline $\mathrm{LI}_{17} \mathrm{~Pb}_{83}$ & 1.3 & Attractive \\
\hline \multicolumn{3}{|l|}{ Solid Breeders } \\
\hline $\mathbf{L}_{2} \mathbf{O}$ & 1.1 & Medium Risk \\
\hline $\mathrm{LI}_{2} \mathrm{O}(+\mathrm{Be})$ & 1.3 & Attractive \\
\hline $\operatorname{LAIIO}_{2}$ & 0.8 & Inposeible \\
\hline $\mathrm{LIAlO}_{2}\left(+2 \mathrm{r}_{5} \mathrm{~Pb}_{3}\right)$ & 1.04 & Rejected \\
\hline $\mathrm{LAAlO}_{2}(+\mathrm{Be})$ & 1.08 & H1gh Rdsk \\
\hline
\end{tabular}


and 1.1 respectively. The risk of attaining the breeding feasibility is low to medium. Beryllium can be used to enhance their tritium breeding capability. Development of $\mathrm{LiAlO}_{2}$ appears to involve a very high risk. All previous optimization studies for $\mathrm{LiAlO}_{2}$, using the best neutron multipliers, yield a tritium breeding ratio that is $<1.1$. The same appears to be true for the other ternary ceramics such as $\mathrm{Li}_{2} \mathrm{SiO}_{3}$ and $\mathrm{Li}_{2} \mathrm{TiO}_{3}$.

The feasibility of solid breeders with respect to tritium breeding cannot be assured at present. Since solid breeders offer many attractive features for fusion reactors, programs to resolve the tritium breeding issue should receive high priority.

\section{Sensitivity to Data Uncertainties}

Sensitivity analyses provide an important input to defining and prioritizing the nuclear data requirements. The objective is to estimate the sensitivity of a specific nuclear response to uncertainties in various cross sections and secondary neutron energy and angular distributions. The results of the sensitivity analysis can be used to define the accuracies in nuclear data parameters required to meet an accuracy goal for a nuclear response (e.g., tritium breeding ratio). In addition, if the uncertainties in the available nuclear data base are well defined, sensitivity analysis is a useful tool in defining the accuracy of the tritium breeding ratio estimated for a conceptual design.

The number of sensitivity studies on fusion blanke ts is rather limited. 28-39 However, reliable tools have been developed, and the recent availability of quantitative information on nuclear data uncertainties in ENDF/B files should encourage additional sensitivity studies in the future. From the available literature, we summarize below some of the results on the sensitivity of the tritium breeding ratio to uncertainties in nuclear data.

This section would have been more easily written if sensitivity studies were available for the most recent blanket designs discussed in earlier sections. Since this is not the case, we have to summarize portions of sensitivity studies performed for earlier varsions of blanket designs based, in some cases, on cross-section sets that have undergone some changes in recent years. However, the results are useful in pointing out some important 
trends. We will select results from studles performed for fast and thermal systems and with and without neutron multipliers to show the differences in sensitivity to nuclear data.

Alsmiller et al. ${ }^{35}$ compared the cross-section sensitivity for the two blanket systems described in Table XI. The first (ORNL) is based cal natural lithium with vanadium or niobium as a structural maierial. Note that the amount of structure indicated is much less than that predicted for the more recent designs. This system can be classified as a "fast" system in which "Li provides large contribution to tritium breeding. With niobium, $T_{6}=0.9, T_{7}=$ 0.6 ; while with vanadium, $T_{6}=0.94$ and $T_{7}=0.61$. The second (LASL) uses beryllium as a neutron multiplier and lithium as a breeding material. The spectrum in the breeding zone is much softer than in the first design, resulting in $T_{6}=0.91$ and $T_{7}$ of only 0.13 . Table XII lists the cross section uncertainties assumed by Alsmiller et al. and also specifies the corresponding cross section varied to maintain a constant total cross section. The estimated uncertainties in the breeding ratio are given in Table XIII. Note that an earlier study by the same authors showed that, of all the ${ }^{7} \mathrm{Li}$ partial cross sections only the ${ }^{7} \mathrm{Li}\left(\mathrm{n}, \mathrm{n}^{-} \alpha\right) \mathrm{t}$ sensitivity was appreciable. The conclusions can be summarized as follows:

- The available ${ }^{6} \mathrm{Li}(n, \alpha) t$ cross section introduces an uncertainty of less than a few tenths of a percent in the breeding ratio for both the fast and thermal designs considered.

- The sensitivity profiles for ${ }^{7} \operatorname{Li}\left(n, n^{\prime} \alpha\right) t$ are not very system dependent and have a shape approximately similar to that of the cross section itself. However, the resultant uncertainty in the magnitude of the tritium breeding ratio is system dependent (since $T_{7} / T$ is system dependent). A $20 \%$ change in the ${ }^{7} \mathrm{Li}\left(\mathrm{n}, \mathrm{n}^{-} \alpha\right) \mathrm{t}$ cross section results in $\sim 6 \%$ change in the breeding ratio in a fast system and $\sim 0$ to $2 \%$ change in a thermal system.

- The uncertainties in the carbon elastic and inelastic cross sections Indicated in Table XII result in an uncertainty in the breeding ratio of $0.6 \%$ in the LASL design, which uses graphite as a moderator. 
Table XI. Description of Two Blanket Concepts for Sensitivity. (Analysis performed by Alsmiller, et al ${ }^{35}$.)

\begin{tabular}{|c|c|c|c|c|}
\hline \multirow[b]{2}{*}{ Zone } & \multicolumn{2}{|c|}{$\mathrm{ORNL}^{\mathrm{a}}$} & \multicolumn{2}{|r|}{ LASL $^{b}$} \\
\hline & $\begin{array}{l}\text { Outer Radiuse } \\
(\mathrm{cm})\end{array}$ & Composition ${ }^{d, e}$ & $\begin{array}{l}\text { Outer Radius } \\
(\mathrm{cm})\end{array}$ & Conposition ${ }^{d}$ \\
\hline $\begin{array}{r}1 \\
2 \\
3 \\
4 \\
5 \\
6 \\
7 \\
8 \\
9 \\
10 \\
11 \\
12\end{array}$ & $\begin{array}{l}280 \\
350 \\
350.25 \\
380.25 \\
380.5 \\
420.5 \\
420.75 \\
450.75 \\
451\end{array}$ & $\begin{array}{l}\text { Plabma } \\
\text { Vacuun } \\
\text { Struc ture } \\
99 \% \text { L + } 1 \% \text { Struc ture } \\
\text { Structure } \\
\text { Graphite } \\
\text { Structure } \\
99 \% \text { L }+1 \% \text { structure } \\
\text { Structure }\end{array}$ & $\begin{array}{l}15 \\
29.9 \\
30 \\
30.4 \\
40 \\
62 \\
68 \\
70 \\
110 \\
115 \\
117 \\
155\end{array}$ & 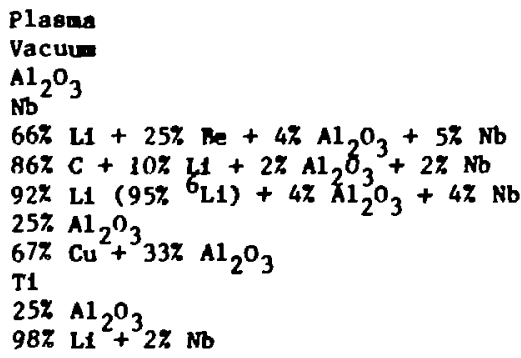 \\
\hline
\end{tabular}

aak Rudge National Laboratory blanket design. ${ }^{3}$

bos Alamos Sclentific Laboratory theta-pinch reactor blanket design. 4

Calculations performed in 1-D cylindrical geometry.

All composition percentages are by volume and all lithium is natural ifthim except where noted.

estruc ture is niobium or vanadium. 
Table XII. Cross-Section Uncertainties Assumed for Various Partial Cross Sections (Analysis performed by Alsmiller, et al ${ }^{35}$.)

\begin{tabular}{|c|c|c|c|c|}
\hline Element & $\begin{array}{l}\text { Cross-Section } \\
\text { Type Var1ed }\end{array}$ & $\begin{array}{c}\text { Energy Range } \\
(\mathrm{MeV})\end{array}$ & $\begin{array}{c}\text { Percent Increase } \\
\text { In Varted } \\
\text { Cross Section } \\
\text { oc }\end{array}$ & $\begin{array}{l}\text { Cross Section } \\
\text { Type Varied to } \\
\text { Compensate }\end{array}$ \\
\hline $6_{\mathrm{L} 1}$ & $\Sigma(n, \tau) \alpha$ & $\begin{array}{l}<1 \times 10^{-7} \\
10^{-7}-10^{-2} \\
10^{-2}-10^{-1} \\
10^{-1}-3 \times 10^{-1} \\
3 \times 10^{-1}-5 \times 10^{-1} \\
5 \times 10^{-1}-7 \times 10^{-1} \\
7 \times 10^{-1}-1 \times 10^{0} \\
1 \times 10^{0}-1 \times 10^{0} \\
1.7 \times 10^{0}-1.4 \times 10^{1}\end{array}$ & $\begin{array}{l}0.5 \\
1.0 \\
1.0-2.0^{\mathrm{b}} \\
5.0 \\
5.0-10^{\mathrm{b}} \\
10-15 \\
15 \\
15-10^{\mathrm{b}} \\
10\end{array}$ & $\begin{array}{l}\Sigma_{\text {Total }} \\
\text { Coll1510n }\end{array}$ \\
\hline$\nu_{11}$ & $\Sigma_{\left(n, n^{-}\right) \alpha, t}$ & Al1 Energies & 20 & $\Sigma_{\text {Elastic }}$ \\
\hline 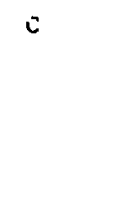 & $\Sigma_{\text {Elastic }}$ & $\begin{array}{l}<4.8 \\
4.8-9.0 \\
9.0-15\end{array}$ & $\begin{array}{l}3.0 \\
5.0 \\
15\end{array}$ & $\begin{array}{l}\Sigma_{\text {Total }} \\
\text { Collision } \\
\Sigma_{\text {Inelastic }}\end{array}$ \\
\hline be & $\Sigma_{\left(n, 2 n^{-}\right)}$ & $\begin{array}{l}1.85-6.4 \\
6.4-14\end{array}$ & $\begin{array}{l}10 \\
10-15^{\mathrm{b}}\end{array}$ & $\Sigma_{\text {Elastic }}$ \\
\hline F & $\begin{array}{l}\Sigma_{\text {Iotal }} \\
\text { Coll1s1on }\end{array}$ & All Energles & 20 & \\
\hline
\end{tabular}

See diacussion in text.

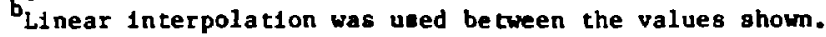


Tâtle XIII. Breeding-Ratio Uncertainties Due to the Cross Section Variations Shown in Table XII.

\begin{tabular}{|c|c|c|c|c|}
\hline \multirow[b]{2}{*}{ Element } & \multirow[b]{2}{*}{$\begin{array}{c}\text { Breeding } \\
\text { Material } \\
J\end{array}$} & \multicolumn{3}{|c|}{$\frac{\delta{ }_{f}}{R}(1 n$ percent $)$} \\
\hline & & $\begin{array}{l}\text { ORNL } \\
\text { DeE1gn } \\
\text { W1 th Nb }\end{array}$ & $\begin{array}{l}\text { OKNL } \\
\text { Design } \\
\text { With v }\end{array}$ & $\begin{array}{l}\text { LASL } \\
\text { DeGIgn }\end{array}$ \\
\hline \multirow[t]{3}{*}{$\sigma_{L 1}$} & ${ }^{6} \mathrm{LI}$ & 0.14 & 0.07 & 0.19 \\
\hline & $7_{L 1}$ & -0.01 & -0.01 & 0.00 \\
\hline & ${ }^{6} L 1$ and $7_{L 1}$ & 0.13 & 0.06 & 0.19 \\
\hline \multirow[t]{3}{*}{$7_{L 1}$} & ${ }^{6} L 1$ & 0.26 & 0.35 & 0.02 \\
\hline & $7_{L 1}$ & 5.60 & 5.56 & 2.42 \\
\hline & ${ }^{6} L_{1}$ and $7_{L 1}$ & $5.80^{\circ}$ & 5.91 & 2.44 \\
\hline \multirow[t]{3}{*}{ c } & $6_{L 1}$ & & & $=0.82$ \\
\hline & $7_{L 1}$ & & & 0.24 \\
\hline & ${ }^{6} \mathrm{LI}$ and $7_{L_{1}}$ & & & -0.58 \\
\hline \multirow[t]{3}{*}{$\mathrm{Be}$} & $6_{L 1}$ & & & 2.51 \\
\hline & $7_{L 1}$ & & & -0.18 \\
\hline & ${ }^{6} L_{1}$ and $7_{L_{1}}$ & & & 2.33 \\
\hline
\end{tabular}


Pelloni ${ }^{39}$ has performed a recent sensitivity study for a variation of two blanket design options considered for INTOR. ${ }^{26}$. The first design is based on $\mathrm{Li}_{2} \mathrm{SiO}_{3}$ as a breeding material and lead as a neutron multiplier. The second uses $\mathrm{Li}_{17}{ }^{\mathrm{Pb}} 83$ as a breeding material. Both concepts have water coolant $\left(\mathrm{D}_{2} \mathrm{O}\right.$ and $\mathrm{H}_{2} \mathrm{O}$ in different regions) and stainless steel 304. The dimensions and material compositions used by Pelloni in 1-D calculations are shown in Table XIV. Both systems are of the thermal type, with $\mathrm{T}_{7}=0.013$. The ${ }_{\mathrm{Li}}(\mathrm{n}, \alpha)$ t reaction rate per fusion neutron is $\mathrm{T}_{6}=1.16$ for $\mathrm{Li}_{2} \mathrm{SiO}_{3}$ and $\mathrm{T}_{6}=$ 1.32 for $\mathrm{Li}_{17} \mathrm{~Pb}_{83^{\circ}}$. The sensitivity to the ${ }^{7} \mathrm{Li}$ data is not important in this system. Table XV gives the percentage change in the tritium breeding ratio due to $1 \%$ change in the partial cross sections of ${ }^{6} \mathrm{Li}, \mathrm{Pb}, \mathrm{Fe}, \mathrm{H}, \mathrm{O}$ and $\mathrm{Al}$.

As expected, Table XV shows that the tritium breeding ratio increases with increasing the $(n, 2 n)$ and/or decreasing the $(n, \gamma)$ cross sections. The breeding ratio is most sensitive in both systems to the $\mathrm{Pb}(\mathrm{n}, 2 \mathrm{n})$ cross section. The change in the breeding ratio is $\sim 15$ to $20 \%$ of the change in the $\mathrm{Pb}(\mathrm{n}, 2 \mathrm{n})$ cross section. For the $\mathrm{Li}_{2} \mathrm{SiO}_{3}$ system, the next most important reactions are the $(n, 2 n)$ and $(n, \gamma)$ in the elements of stainless steel, particularly iron. The changes in the breeding ratio are $+0.06 \%$ and $-0.05 \%$ due to $1 \%$ increase in the $(n, 2 n)$ and $(n, y)$ cross sections, respectively. The results of Pelloni indicate that the sensitivity to ${ }^{6} \mathrm{Li}$ is very small.

Considering typical uncertainties in lead cross sections of $\sim 7 \%$ for $(n, 2 n)$ and $\sim 10 \%$ for elastic and inelastic cross sections, the corresponding uncertainty in the breeding ratio is $\sim 1.4 \%$. Typical uncertainties in iron cross sections of $\sim 15 \%$ in elastic, inelastic, and $(n, 2 n)$ and $\sim 10 \%$ in $(n, \gamma)$ give an uncertainty in the breeding ratio of $\sim 0.6 \%$ to $\sim 1.5 \%$. Since the uncertainties in the $(n, 2 n)$ and $(n, \gamma)$ cross sections are not correlated, they both can be lower or higher or one of them higher and the other lower than the presently available values. This, of course, affects the estimate of uncertainty in the breeding ratio.

In addition to the uncertainties in the cross sections discussed above, errors in the secondary neutron energy and angular distributions are of serious concern. Obviously, the neutron emitting reactions of all materials that contribute significantly to determining the neutron transport in the blanket can potentially affect the breeding ratio. of particular importance are the secondary neutron energy distributions for ${ }^{7} \operatorname{Li}\left(n, n^{-} \alpha\right) t$ and for the 
Table XIV. INTOR Blanket Models used by Pelloni 39

\begin{tabular}{|c|c|c|c|c|c|}
\hline \multicolumn{3}{|c|}{$\mathrm{LI}_{2} \mathrm{~S} \mathrm{O}_{3}$ Blanket } & \multicolumn{3}{|c|}{$\mathrm{LI}_{17} \mathrm{~Pb}_{83}$ Blanke $\mathrm{C}$} \\
\hline Zone & $\begin{array}{c}\text { Thickness } \\
\text { cm }\end{array}$ & Compusition & Zone & $\begin{array}{c}\text { Thickness } \\
\text { cm }\end{array}$ & Composition \\
\hline 1 & 220 & Plasma & 1 & 220 & Plasma \\
\hline 2 & 30 & Vacuum & 2 & 30 & Vacuum \\
\hline 3 & 13 & $100 \% \mathrm{ss}$ & 3 & 3 & $80 \% \mathrm{Al}+20 \% \mathrm{H}_{2} \mathrm{O}$ \\
\hline 4 & 9.1 & $\begin{array}{l}60.7 \% \mathrm{~Pb}+7.8 \% \mathrm{D}_{2} \mathrm{O} \\
+10 \% \mathrm{SS}+21.5 \% \mathrm{po1d}\end{array}$ & 4 & 40 & 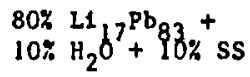 \\
\hline 5 & 6.2 & $\begin{array}{l}28.6 \% \mathrm{L1}_{2} \mathrm{SHO}_{3}+22.1 \% \\
\mathrm{H}_{2} \mathrm{O}+11.2 \% \mathrm{Ss}+16.6 \% \\
\mathrm{He}+21.5 \% \text { vold }\end{array}$ & 5 & 12 & $100 \%$ ss \\
\hline 6 & 6.2 & $\begin{array}{l}24.5 \% \mathrm{L1}_{2} \mathrm{S1O}_{3}+27.9 \% \\
\mathrm{H}_{2} \mathrm{O}+11.1 \% \mathrm{Ss}+15 \% \\
\mathrm{He}+21.5 \% \text { vold }\end{array}$ & & & \\
\hline 7 & 6.2 & $\begin{array}{l}12.3 \% \mathrm{Li}_{2} \mathrm{~S}_{3}+29.7 \% \\
\mathrm{H}_{2} \mathrm{O}+11 \% \mathrm{SS}^{3}+25.5 \% \mathrm{He} \\
+21.5 \% \text { void }\end{array}$ & & & \\
\hline 8 & 12 & $100 \%$ SS & & & \\
\hline
\end{tabular}

$a_{\text {Lithium is enriched to } 30 \%{ }^{6} \text { LI. }}$ 
Table XV. Sensitivities 39 of Tritium Production Rate to Partial Cross Section Uncertainties for the Two INTOR Designs of Table XIV. (Percent per $1 \%$ Cross Section Increase.)

\begin{tabular}{|c|c|c|c|c|c|c|c|c|c|}
\hline \multicolumn{4}{|c|}{$\mathrm{LH}_{2} \mathrm{SHO}_{3}$ Concept } & \multicolumn{6}{|c|}{$\mathrm{Lt}_{17} \mathrm{~Pb}_{83}$ Concept } \\
\hline $\begin{array}{c}\text { Cross Section } \\
\text { Type }\end{array}$ & $\mathrm{Pb}$ & Fe & ${ }^{6} \mathrm{LI}$ & $\mathrm{Pb}$ & $\mathrm{Fe}$ & ${ }^{6} \mathrm{LL}$ & H & 0 & Al \\
\hline$(n, n)$ & 0.000 & 0.011 & -- & 0.029 & 0.016 & -- & 0.057 & 0.003 & -0.006 \\
\hline$\left(n, n^{-}\right)$ & -0.001 & -0.000 & - & -0.013 & -0.012 & - & - & -0.011 & -0.057 \\
\hline$(n, 2 n)$ & 0.195 & 0.059 & -- & 0.149 & 0.008 & -- & -- & -- & 0.003 \\
\hline$(n, \gamma)$ & - & -0.045 & - & $\sim$ & -0.078 & -- & - & - & - \\
\hline$(n, t)$ & -- & - & 0.001 & - & -- & 0.006 & - & -- & - \\
\hline
\end{tabular}


$(n, 2 n)$ reaction in neutron multipliers (e.g., Be and $P b)$. Unfortunately, very few studies have been performed in this area and deriving quantitative conclusions on the uncertainty in the breeding ratio due to errors in the secondary neutron energy and angular distributions is difficult at present. It should be noted, however, that these errors are generally much larger than those in the reaction cross sections and are thus likely to contribute more to the uncertainty in the breeding ratio.

Steiner and Tobias ${ }^{28}$ examined the sensitivity of the breeding ratio to the energy distributions of the secondary neutrons produced by the ${ }^{7} \mathrm{Li}\left(\mathrm{n}, \mathrm{n}^{-} a\right) t$ reaction. They varied the nuclear temperature, $\theta(E)$, in an evaporation model that describes this energy distribution by $\pm 50 \%$. Increasing $\theta(E)$ by $50 \%$ results in a harder spectrum and an increase in $T_{7}$ by $2.8 \%$. The harder spectrum increases the fraction of $\mathrm{T}_{7}$ contributed by the secondary neutrons from the ${ }^{7} \mathrm{Li}\left(n, n^{\prime} \alpha\right) t$ reaction from 0.15 to 0.18 . Decreasing $\theta(E)$ produces a softer spectrum and decreases $T_{7}$ by $\sim 7 \%$. The tritium production rate in ${ }^{6} \mathrm{Li}$ remained unchanged. Markovsii ${ }^{40}$ obtained similar results. The importance of the accuracy in the energy distribution of the ${ }^{7} \mathrm{Li}\left(\mathrm{n}, \mathrm{n}^{\prime} \alpha\right) \mathrm{t}$ is 1 imited to non-thermal blankets.

The accuracy of $T$ is affected by the uncertainty in the energy distributions of the secondary neutrons of the $(n, 2 n)$ reaction when a significant fraction of these secondary neutrons have an energy well above the threshold for the $(n, 2 n)$ or the $7 \operatorname{Li}\left(n, n^{-} \alpha\right) t$ reactions. The effect can be expected to be the largest for beryllium, whose $(n, 2 n)$ reaction has a threshold energy of only $2.8 \mathrm{MeV}$. Soran et al. 41 examined the sensistivity of $\mathrm{T}$ in a thermal-type blanket (similar in many respects to the LASL design discussed earlier) to uncertainties in the $\operatorname{Be}(n, 2 n)$ secondary energy distribution. They considered two data sets in which the average energy of the secondary neutrons are $\sim 4$ $\mathrm{MeV}$ and $\sim 7 \mathrm{MeV}$. They found $\sim 6 \%$ difference in the breeding ratio.

\section{Recomended Effort}

A serious R\&D effort is necessary to demonstrate the feasibility of achieving adequate tritium breeding in fusion blankets. While some present blanket concepts such as $\mathrm{Li}_{17} \mathrm{~Pb}_{83}$ provide adequate assurance of the feasibility of tritium breeding, a number of other concepts such as solid breeders have too small a breeding margin to assure success. In addition to 
tritium breeding, the selection of materials and design concepts depends on a number of critical requirements discussed in an earlier section (e.g., tritium release). Therefore, the fusion blanket R\&D program has to investigate the critical issues such as tritium breeding and tritium release (see Table III) simultaneously for a number of materials and design concepts. Thus, a neutronics $R \& D$ program is a key part of the critical path leading to the selection of a viable blanket design.

Areas for the tritium breeding $R \& D$ neutronics effort are sumiarized in Table XVI. The effort should focus on:

A. Reducing the uncertainties in predicting $T$.

B. Improving the predictability of the uncertainty in $T$.

The two areas are, of course, interrelated. For example, the effort to improve the predictability of the uncertainty in $\mathrm{T}$ will lead to a better definition of areas where effort is needed to reduce uncertainties.

There are three sources of error that contribute to the uncertainty in $T$ :

1. Design Definition

2. Calculations

3. Nuclear Data

The uncertainties of the design definition comes from the many yet unresolved technology choices for reactor components that can impact tritium breeding (e.g., neutral beams vs. rf and limiter vs. divertor) and from the lack of some engineering details in present conceptual designs. The present overall $R \& D$ strategy for fusion is such that design definition should continualiy improve over the next several years. Some technology choices are likely to remain open for sometime, however, and the neutronics analyst has to develop ways to cope with the situation.

The second source of uncertainty comes from the calculations. The critical phase of the calculations is neutron transport, 1.e., predicting the neutron flux. There are some inherent errors in methods/codes due to numerical techniques, averaging, discrete treatment of continuous variables, etc. There are also errors introduced by the approximations made by the 
Table XVI. Needed Neutronics Effort on Tritium Breeding

A. Reduce Uncertalntles in Predicting $T$

1. Desiggn Definition

- Narrow Materials and Design Concepto

- Greater Englneering Detalla

2. Calculations

- Improve He thods (neutron transport)

- More Detalled Modeling

3. Nuclear Data

- Measurements

- Evaluation

- Data Representation and Processing

B. Improve Predictability of Uncertaincy in $T$

1. Integral Experiments

- Basic Experiments

- Engineering Experiments

- Mockup

2. Sensitivity Analysis

- Improve Method

- Perform Sensitivity Studies (geometry, material composition, cross sections, secondary neutron spectra, etc.) 
radiation transport analyst in describing the problem. The most common of these relates to the approximations in the geometrical modeling of the physical system. These approximations are of ten motivated by cost considerations, but sometimes are dictated by limitations on the input description for the transport code. These topics were discussed by several authors (see for example reference 9). The discrete ordinates me thod is normally used for $1-D$ and 2-D problems while Monte Carlo is the method of choice for 3-D problems. An important need that has been identified is to improve Monte Carlo codes to facilitate input specifications for geometric representation of specialized fusion geometries. For example, the input description for representing tori in both tokamaks and particular types of major penetrations in tokamaks and mirrors can be simplified.

The uncertainties from nuclear data have been discussed in earlier sections. The following section will discuss the improvement needs for nuclear data. It should be noted that in addition to errors in basic data, errors can also be introduced in data representation and processing.

One of the most serious shortcomings at present is the lack of adequate predictions of the uncertainties in the tritium breeding ratio. The only effort in this area has been limited to a number of sensitivity studies that were reviewed in an earlier section. It is presently very difficult to define quantitatively the accuracy needs in specific cross sections, energy spectra, etc. to meet the stated accuracy goal for the breeding ratio. This situation must be remedied by high priority $R \& D$. The two key elements of this $R \& D$ should be integral breeder neutronics experiments and sensitivity analysis.

The types of integral experiments of immediate need are:

- "Clean" experiments that provide definitive Information about the uncertainties in specific cross sections in the energy range 0-14 $\mathrm{MeV}$.

- Simple engineering experiments that include key engineering features but the configuration is simple enough to be accurately calculated. These experiments should be performed with a $14 \mathrm{MeV}$ neutron source and will provide an estimate of the difference between measured and calculated values for tritium production. 
"Mock-up" experiments may ultimately be required to validate the neutronics design and performance prediction. However, the geometrical complexity involved in a realistic mock-up makes it unlikely that discrepancies be tween calculations and measurement can be resolved. Furthermore, mock-up experiments will encounter serious difficulties in attempting to realistically simulate a fusion (volumetric) neutron source. Therefore, the role of mock-up experiments in fusion blanket neutronics remains to be evaluated. It must be noted that all types of integral experiments will fall short of direct experimental demonstration of the achievable breeding ratio in an actual reactor, where penetrations and other geometrical effects will affect the tritium production. Extrapolation will, of course, have to be resorted to. Howevel, such extrapolation will be adequate only if the tritium breeding margin exceeds the estimated uncertainties.

A number of very simple integral experiments have been performed and were reviewed by Jarvis. ${ }^{42}$ The Japanese fusion program has made a significant step forward in the area of integral experiments. An intense $14 \mathrm{MeV}$ neutron source was constructed in a versatile facility dedicated for fusion neutronics. The facility is now operational and initial experiments 45 have begun. The United states program is in the stage of planning for integral breeder neutronics experiments.

\section{Nuclear Data Needs}

The fusion program has been fortunate to have the extensive methods and data information base that has been developed over the past thirty years in the fission and weapons program. In the late 1960's and early 70's, the additional data needs for fuston in terms of materials, energy range, type of data, etc. were defined. Significant progress has been made over the past decade in satisfying many of these needs.

The nuclear data program should be aimed at two areas: 1) improving the broad data base for candidate fusion materials, and 2) satisfying high priority requests for high accuracy measurements in specific materials. A program to improve the overall data base is necessary for several reasons. There is presently a diversity of candidate materials and design concepts. The probability of selecting a number of materials has changed and will continue to change over the years. Furthermore, the sensitivity of estimated 
parameters such as the tritium breeding ratio are very system dependent. As the characteristics of the system change and become clearer in the future, it is likely that our priority list of very specific needs will be different.

Satisfying high priority requests for high accuracy measurements in specific materials should continue to be a part of the nuclear data effort. However, the list of priority requests must always be kept under review. Fur thermore, methods for generating the priority requests should be improved. More specifically, integral neutronics experiments and sensitivity studies should be relied upon in developing priorities and accuracy requirements. Several reviews of the data needs were performed recently (see, for example references $42-44,9,46)$. We briefly review below the highlights of the data needs for tritium breeding.

'lable XVII lists the elements of importance for tritium breeding. The author attempted to limit the number of materials, but the list remains long because of the large number of tritium breeding blanket concepts that are still under very active consideration in fusion development. For each material, the probability of eventually using it in a fusion reactor is given on three scales: high, medium, and low. This probability is derived based on all presently known considerations of engineering feasibility issues. A priority for the data needs for each material is given on a scale from 1 to 3 with 1 designating the highest priority. The priority for the data needs of each material combines considerations of a) the probability of eventually using the material in the blanket, b) the effect of the material on the tritium production rate, and c) the uncertainties in the presently available data. For example, hydrogen has a very high probability of use as an element of the water coolant, and it does affect significantly tritium production, but the accuracies of available data are excellent. Therefore, the priority for the data needs of hydrogen is very low. The materials included in Table XVII cover not only the blanket materials but also those in components that affect tritium production in the blanket, such as the first wall, limiter, rf.

The type of data needed are those that affect the neutron transport, 1.e. 1) total, 2) elastic, 3) inelastic, 4) neutron emission $\left[\sigma_{e m}, P\left(E^{-}\right), d \sigma / d \Omega\right]$, and 5) total parasitic neutron absorption; as well as the tritium-producing reaction cross sections, ${ }^{6} \mathrm{Li}(\mathrm{n}, \alpha) \mathrm{t}$ and ${ }^{7} \mathrm{Li}\left(n, n^{\circ} \alpha\right) t$. Some of this data and other types of data are, of course, needed for nuclear heating radiation damage, etc. 
Table XVII. Probability of Use and Priority of Data Needs for Elements of Importance to Tritium Breeding

\begin{tabular}{|c|c|c|c|}
\hline Elenent & $\begin{array}{l}\text { Probabilltty } \\
\text { of Use }\end{array}$ & $\begin{array}{l}\text { Prior1ty for } \\
\text { Daca Needs }\end{array}$ & Commento \\
\hline \multicolumn{4}{|l|}{ L1 th1um/L1 th1 um Compounds } \\
\hline $\begin{array}{l}\text { Li thium } \\
\text { Lead } \\
\text { Oxygen } \\
\text { Aluminum. } \\
\text { S1licon } \\
\text { Z1rconium } \\
\text { T1 taniun } \\
\text { Neutron Mul tiplier }\end{array}$ & $\begin{array}{l}\mathrm{H} \\
\mathrm{H} \\
\mathrm{H} \\
\mathrm{M} \\
\mathrm{M} \\
\mathrm{M} \\
\mathrm{L}\end{array}$ & $\begin{array}{l}1 \\
1 \\
3 \\
1 \\
1 \\
1 \\
1\end{array}$ & 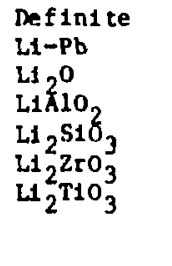 \\
\hline $\begin{array}{l}\text { Beryl11uro } \\
\text { Lead } \\
\text { B1 smu th } \\
\text { Zirconium }\end{array}$ & $\begin{array}{l}\text { H } \\
\text { M } \\
\text { L } \\
\text { L }\end{array}$ & $\begin{array}{l}1 \\
1 \\
2 \\
3\end{array}$ & $\begin{array}{l}\mathrm{B1}-\mathrm{Pb} \\
2 r_{5} \mathrm{~Pb}_{3}\end{array}$ \\
\hline Coolant & & & \\
\hline $\begin{array}{l}\text { Helluw } \\
\text { Hydrogen } \\
\text { Oxygen }\end{array}$ & $\begin{array}{l}M \\
H \\
H\end{array}$ & $\begin{array}{l}3 \\
3 \\
3\end{array}$ & $\begin{array}{l}\mathrm{H}_{2} \mathrm{O} \\
\mathrm{H}_{2} \mathrm{O}\end{array}$ \\
\hline Structural Matertal & & & \\
\hline $\begin{array}{l}\text { Iron } \\
\text { Chrom1um } \\
\text { N1 ckel } \\
\text { Manganese } \\
\text { Vanad1um } \\
\text { N1obium }\end{array}$ & $\begin{array}{l}\mathrm{H} \\
\mathrm{H} \\
\mathrm{H} \\
\mathrm{H} \\
\mathrm{H} \\
\mathrm{H} \\
\mathrm{L}\end{array}$ & $\begin{array}{l}1 \\
2 \\
2 \\
2 \\
1 \\
3\end{array}$ & $\begin{array}{l}\text { ss } \\
\text { ss } \\
\text { ss } \\
\text { ss }\end{array}$ \\
\hline Moderator/Reflector & & & $\mathrm{SS}, \mathrm{H}_{2} \mathrm{O}$ \\
\hline $\begin{array}{l}\text { Carbon } \\
\text { In-Vessel Components }\end{array}$ & M & 3 & \\
\hline $\begin{array}{l}\text { Copper } \\
\text { Vanadium } \\
\text { Niobium } \\
\text { Tungsten } \\
\text { Tantalum }\end{array}$ & $\begin{array}{l}H \\
M \\
M \\
M \\
L\end{array}$ & $\begin{array}{l}2 \\
2 \\
2 \\
3 \\
3\end{array}$ & \\
\hline
\end{tabular}

a Judgement on the probability of using the material in fusion blankets: H=high, M-medium, Lmlow.

biority for data needs takes into account of (a) the probability of using the mater1al, (b) effect on tritium breeding, and (c) uncertainties in presently avallable data. 
The energy range of interest extends from thermal energies to at least the average energy of the D-T neutrons, 1.e., $14 \mathrm{MeV}$. It should also be noted that there is a considerable width in the spectrum of the source neutrons emitted from D-T plasmas significantly heated or driven by injecting energetic deuterons. Therefore, the high energy limit foi nuclear data should extend to $\sim 15$ or $16 \mathrm{MeV}$. Sensitivity studies indicate that the 9 to $15 \mathrm{MeV}$ range is the most important for predicting the neutron transport. Available data in this range are less adequate than those below $9 \mathrm{MeV}$. The low energy range, 0 to $100 \mathrm{keV}$, is very important for many of the recent breeding blanket concepts, particularly the "thermal" type discussed earlier. In some of these concepts, $\sim 80 \%$ of the tritium production is contributed by neutrons of energies $<4 \mathrm{eV}$, inducing the ${ }^{6} \mathrm{Li}(\mathrm{n}, \alpha)$ t reaction.

The accuracy goal for predicting the tritium breeding ratio is $2 \%$. Thus, the accuracy of nuclear data should be such that the contribution of nuclear data uncertajnties to the error in tritium breeding ratio estimates 1 s $\sim 1 \%$ or less. Specific accuracy requirements for material, reaction, energy range, etc. can be derived only from future integral breeding experiments and sensitivity studies. From the limited studies we have, it appears that an accuracy of $\sim 5$ to $10 \%$ in data for neutron transport may be sufficient. Exceptions can be noted for several key blanket materials such as beryllium and lead where accuracies of $\sim 3 \%$ are required. 44

${ }^{6} \mathrm{Li}$ and ${ }^{7} \mathrm{Li}$ are obviously critical to tritium breeding. The status of the ${ }^{6} \mathrm{Li}(n, \alpha) t$ cross section data appears adequate. As discussed earlier, avallable data appear to introduce an uncertainty of less than a few ten ths of a percent in the tritium breeding ratio for present candidate designs. The importance of $7_{\mathrm{Li}}$ depends critically on the blanket system considered. In the thermal system, ${ }^{7} \mathrm{Li}$ contribution is almost negligible. However, for systems such as those with natural $1 i$ thium and $\mathrm{Li}_{2} \mathrm{O}$, the ${ }^{7} \mathrm{Li}\left(\mathrm{n}, \mathrm{n}^{\circ} \alpha\right)$ tcontribution can be more than one-third the breeding ratio. The avallable accuracies for the ${ }^{7} \operatorname{li}\left(n, n^{-} \alpha\right)$ tcross section and secondary neutron energy distribution are not adequate. The required accuracy in this cross section is $\sim 3 \%$. 


\section{Acknowledgenen ts}

The author thanks his colleagues, Drs. J. Jung and Y. Gohar, for many useful comments. Dr. Jung has graciously provided the author with some important results from his recent work prior to this publication. The efforts of Ms. Lee Ann Legerski in typing and organizing this manuscript are greatly appreciated. 


\section{References}

1. B. Badger, et al., "UWMAK-I," UWFDM-68, University of Wisconsin (1973).

2. D. Steiner, "Analysis of a Benchmark Calculation of Tritium Breeding in a Fusion Reactor Blanket-The U.S. Contribution," ORNL-TM-4177, Oak Ridge National Laboratory (1973).

3. D. Steiner, M. Tobias, Nucl. Fusion 14, 2(1974) 153.

4. C. Baker, et al., "STARFIRE-A Commercial Tokamak Fusion Power Plant Study," ANL/FPP--80-1, Argonne National Laboratory (1980).

5. M. Abdou, et al., "A Demonstration Tokamak Power Plant Study-Interim Report," ANL/FPP/TM-154, Argonne National Laboratory (1982).

6. "International Tokamak r.eactor - Phase I," International Atomic Energy Agency, Vienna (1982).

7. W. F. Vogelsang, "Breeding Ratio, Inventory, and Doubling Time in a D-T Fusion Reactor," Nucl. Tech ${ }_{\star 1} 15470$ (1972).

8. R. Clemmer, "TCODE - A Computer Code for Analysis of Tritium and Vacuum Systems for Tokamak Fusion Reactors," ANL/FPP/TM-110, Argonne National Laboratory (1978).

9. M. A. Abdou, "Problems of Fusion Reactor Shielding," GTFR-10, Georgia Institute of Techrology (1979).

10. J. Gilligan, K. Evans, Personal Communication (1982).

11. M. A. Abdou, D. Graumann, "The Choice of Coolant in Commercial Tokamak Power Plants," Proc. 4th Topical Meeting on the Technology of Controlled Nuclear Fusion, CONF-801011, Vol. III, p. 1740 (1980).

12. J. Jung, M. Abdou, "Breeding Potential of Candidate Breeding Materials," Nucl. Tech. (to be published).

13. T. Ide, Y. Seki, H. Aida, "Effects of Neutron Streaming through Injection Ports on Neutronics Characteristics of a Fusion Reactor," Proc. 2nd Topical Meeting on the Technology of Controlled Nuclear Fusion, CONF760935-P3, p. 395 (1976).

14. W. M. Stacey, Jr., et al., "U.S. Contribution to the International Tokamak Reactor Phase-I Study," US-INTOR/81-1, Georgia Institute of Technology (1981).

15. M. A. Abdou, "Radiation Considerations for Super-conducting Fusion Magnets," J. Nucl. Mater. 72, 147-167 (1978).

16. M. Abdou, "Nuclear Design of the Blanket/Shield System for a Tokamak Experimental Power Reactor," Nuc1. Techn. 29, 7 (1976). 
17. D. W. Muir, M. E. Wyman, "Neutronic Analysis of a Tritium-Production Integral Experiment," Proc. Symp. Technolog, if Controlled Thermonuclear Fusion Experiments and the Engineering Aspects of Fusion Reactors, CONF72111 , p. 910 (1974).

18. H. Bachmann, U. Fritsher, F. W. Kappler, D. Rusch, H. Werle, H. W. Wiesse, "Neutron Spectra and Tritium Production Measurements in a Lithium Sphere to Check Fusion Reactor Blanket Calculations," Nucl. Sci. Eng. 67, 74 (1978).

19. W. A. Ruepke, "The Consistency of Differential and Integral Thermonuclear Neutronics Data," LA-7067-T, Los Alamos National Laboratory (1978).

20. A. Hemmendinger, C. E. Ragan, J. M. Wallace, Nucl. Sc1. Eng. 70,274 (1979).

21. D. L. Smith, M. Bretscherr, J. W. Meadows, "Measurement of the Cross Section for the $\mathrm{Li}\left(n, n^{\prime} t\right)$ He Reaction in the Energy Range 7-9 MeV" Nucl. Sci. Eng., 78, 359 (1981).

22. M. T. Swinhoe, C. A. Uttley, "Trittum Breeding in Fusion," Proc. Conf. Nuclear Cross Sections for Technology," NBS Special Publication 594, p. 246, National Bureau of Standards (1980).

23. P. G. Young, "Evaluation of $n+{ }^{7} \mathrm{Li}$ Reactions Using Variance-Covariance Techniques," Trans. Am. Nucl. Soc. 39, 272 (1981).

24. Y. Gohar, M. Abdou, "Neutronic Optimization of Solid Breeder Blankets for STARFIRE Design," Proc. 4th Topical Meeting on the Technology of Controlled Nuclear Fusion, CONF-801011, Vol. II, p. 628 (1980).

25. R. W. Conn, G. L. Kulcinski, "UWMAK-I I," UWFDM-112, University of Wisconsin (1975).

26. "International Tokamak Reactor - Phase I," International Atomic Energy Agency, Vienna (1982).

27. M. Abdou, L. Wittenberg, C. W. Maynard, "A Fusion Design Study of NonMobile Blankets with Low Lithium and Tritium Inventories," Nucl. Techn. $26,400(1975)$.

28. D. Steiner, M. Tobias, "Cross-Section Sensitivity of $\operatorname{Tr}$ itium breeding in a Fusion Reactor Blanket: Effects of Uncertainties in Cross-Sections of ${ }^{6} \mathrm{Li},{ }^{7} \mathrm{Li}$, and ${ }^{93} \mathrm{Nb}, "$ Nucl. Fusion 14,153 (1974).

29. D. E. Bartine, E. M. Oblow, F. R. Mynatt, "Radiation-Transport CrossSection Sensitivity Analysis - A General Approach Illustrated for a Thermonuclear Source in Air," Nucl. Sci. Eng. 55, 147 (1974).

30. S. A. W. Gerstl, D. J. Dudziak, D. W. Muir, "Cross-Section Sensitivity and Uncertainty Analysis with Application to a Fusion Reactor," Nucl. Sci. Eng. 62, 137 (1977). 
31. R. Conn, W. M. Stacey, "Variational Me thod for Controlled Thermonuclear Reactor Blanket Studies," Nucl. Fusion 13, 185 (1973).

32. R. G. Alsmiller, J. Barish, T. A. Gabriel, R. T. Santoro, "Comparison of Cross-Section Sensitivities of Breeding Ratios in Fusion-Reactor

Blankets," Trans. Am. Nucl. Soc. 19, 463 (1974).

33. D. E. Bartine, R. G. Alsmiller, C. M. Oblow, F. R. Mynatt, "Cross-Section Sensitivity of Breeding Ratio in a Fusion Reactor Blanket," Nucl. Sci. Eng. 53, 304 (1974).

34. S. A. W. Gerstl, "Blanket Design and Cross-Section Sensitivity Calculations Based on Perturbation Methods," Proc. 1st Topical Meeting on the Technology of Controlled Nuclear Fusion, CONF-740-402-P2, p. 136 (1974).

35. R. G. Alsmiller, R. T. Santoro, J. Barish, T. A. Gabriel, "Comparison of the Cross-Section Senaltivity of the Tritium Breeding Ratio in Various Fusion-Reactor Blankets," Nucl. Sci. Eng. 57, 122 (1975).

36. R. G. Alsmiller, J. Barish, C. R. Weisbein, "Uncertainties in Calculating Heating and Radiation Damage in the Toroidal Field Coll of a Tokamak Experimental Power Reactor Due to Neutron Cross-Section Errors," Nucl. Techn. 34, 376 (1977).

37. B. Arciplani, G. Palmiotti, M. Salvatores, "Neutron Heating Sensitivity to Cross-Section Variations in a Controlled Thermonuclear Reactor Blanket," Nucl. Sci. Eng. 65, 540 (1978).

38. T. Wu, C. W. Maynard, "The Application of Uncertainty Analysis in Conceptual Fusion Reactor Design," Proc. of a Seminar-Workshop on Theory and Application of Sensitivity and Uncertainty Analysis, ORNL/RSIC -42 , Oak Ridge National Laboratory (1979).

39. S. Pellon1, "Cross-Section Sensitivity and Uncertainty Analysis for European INTOR and U.S. FED Designs," GA-Al6685 (1982).

40. D. V. Markovsii, et al., "Influence of Neutron Constants on the Behaviour of a Thermonuclear Reactor Blanket, IAE 2579 (1975).

41. P. D. Soran, et al., "Effect of Be $(n, 2 n)$ Multigroup Treatment on The ta Pinch Blanket Neutronics, Proc. 1st Topical Meeting on the Technology of Controlled Nuclear Fusion, CONF-740402-P2, p. 172 (1974).

42. 0. N. Jarvis, "Nuclear Data Needs for Fusion Reactors," European Appl. Res. Rep., Nucl. Sci. Techn. 3, 127 (1981).

43. "Nuclear Data for Fusion Reactor Technology," IAEA-TECDOC-223, International Atomic Energy Agency (1979).

44. E. T. Cheng, et al., "Magnetic Fusion Energy Program Nuclear Data Needs," GA-NDN-82-005 (1982). 
45. T. Nakamura, et al., "Integral Experiments on Lithium Oxide Spherical Assembly with Graphite Reflector and on Duct Streaming," 3rd IAEA Technical Committee Meeting and Workshop on Fusion Reactor Design and Technology, Tokyo (1981).

46. G. Constantine, "Nuclear Data Requirements for Fusion Reactor Design Neutronics Design, Blanket Neutronics, and Tritium Breeding," Nuclear Data for Fusion Reactor Technology, IAEA-TECDOC-223, In ternational Atomic Energy Agency (1979).

47. H. Liskien, et al., "Determination of ${ }^{7} \mathrm{Li}\left(n, n^{-} t\right)^{4} \mathrm{He}$ Cross Sections," Proceedings of this conference. 